\title{
IL-6 Drives Neutrophil-Mediated Pulmonary Inflammation Associated with Bacteremia in Murine Models of Colitis
}

Sean W. Mateer, ${ }^{* \dagger \dagger}$ Andrea Mathe, ${ }^{* \dagger \ddagger}$ Jessica Bruce, ${ }^{* \dagger \ddagger}$ Gang Liu, ${ }^{* \dagger \ddagger}$ Steven Maltby, ${ }^{* \dagger}$ Michael Fricker, ${ }^{* \dagger \S}$ Bridie J. Goggins, ${ }^{* \dagger \dagger}$ Hock L. Tay, ${ }^{* \dagger}$ Ellen Marks, ${ }^{* \dagger}$ Grace Burns, ${ }^{* \dagger}$ Richard Y. Kim, ${ }^{* \dagger}$ Kyra Minahan, ${ }^{* \dagger}$ Marjorie M. Walker, ${ }^{\dagger \dagger \S}$ Robert C. Callister, ${ }^{* \dagger}$ Paul S. Foster, ${ }^{* \dagger}$ Jay C. Horvat, ${ }^{* \dagger}$ Philip M. Hansbro, ${ }^{* \dagger}$ and Simon Keely ${ }^{* \dagger \dagger}$

From the School of Biomedical Sciences and Pharmacy, ${ }^{*}$ the Priority Research Centre for Digestive Health and Neurogastroenterology, ${ }^{\ddagger}$ and the School of Medicine and Public Health, ${ }^{\S}$ University of Newcastle, Callaghan, New South Wales; and the Hunter Medical Research Institute, ${ }^{\dagger}$ New Lambton Heights, New South Wales, Australia

\author{
Accepted for publication \\ March 23, 2018. \\ Address correspondence to \\ Simon Keely, Ph.D., School of \\ Biomedical Sciences and Phar- \\ macy, University of Newcastle, \\ Hunter Medical Research Insti- \\ tute, Lot 1 Kookaburra Circuit, \\ New Lambton Heights, NSW \\ 2305, Australia. E-mail: simon. \\ keely@newcastle.edu.au.
}

\begin{abstract}
Inflammatory bowel disease (IBD) is associated with several immune-mediated extraintestinal manifestations. More than half of all IBD patients have some form of respiratory pathology, most commonly neutrophil-mediated diseases, such as bronchiectasis and chronic bronchitis. Using murine models of colitis, we aimed to identify the immune mechanisms driving pulmonary manifestations of IBD. We found increased neutrophil numbers in lung tissue associated with the pulmonary vasculature in both trinitrobenzenesulfonic acid - and dextran sulfate sodium-induced models of colitis. Analysis of systemic inflammation identified that neutrophilia was associated with bacteremia and pyrexia in animal models of colitis. We further identified IL- 6 as a systemic mediator of neutrophil recruitment from the bone marrow of dextran sulfate sodium animals. Functional inhibition of IL-6 led to reduced systemic and pulmonary neutrophilia, but it did not attenuate established colitis pathology. These data suggest that systemic bacteremia and pyrexia drive IL- 6 secretion, which is a critical driver for pulmonary manifestation of IBD. Targeting IL-6 may reduce neutrophil-associated extraintestinal manifestations in IBD patients. (Am J Pathol 2018, 188: 1625-1639; https://doi.org/10.1016/j.ajpath.2018.03.016)
\end{abstract}

Inflammatory bowel disease (IBD) is the umbrella term for several chronic inflammatory conditions that predominately affect the gastrointestinal (GI) tract, including Crohn disease and ulcerative colitis. In addition to pathology within the GI tract, IBD patients also exhibit secondary organ pathologies. These are termed extraintestinal manifestations (EIMs) and develop as inflammatory responses in skin, eyes, joints, liver, and lungs. ${ }^{1}$ EIMs are diagnosed in approximately $45 \%$ of IBD patients and can contribute significantly to the morbidity associated with IBD. $^{2}$ In particular, there is a growing appreciation of the prevalence of pulmonary EIMs in IBD. A 2007 systematic review by Black et al ${ }^{3}$ reported cases of respiratory disease in 35\% of IBD patients assessed. Other studies that have aimed to directly access the prevalence of respiratory pathologies in IBD patients report that up to $64 \%$ of IBD patients examined have some form of respiratory pathology, although many of these may be subclinical in nature and thus are missed in routine diagnosis. ${ }^{4-9}$ This has led to a general consensus that respiratory pathologies in IBD patients are more common than currently appreciated, prompting considerable research interest. ${ }^{2-5,7-19}$

The causes and conditions that drive pulmonary EIMs are not known, with current hypotheses suggesting that inflammatory and microbial spillover from the GI tract, attributable to increased intestinal permeability, drives systemic inflammation and immune cell mishoming to

\footnotetext{
Supported by National Health and Medical Research Council project grant APP1128487 and Cancer Institute NSW Career Development Fellowship (S.K.); Hunter Medical Research Institute Bowel of the Ball grant (S.K., A.M., and G.L.); and Emlyn and Jennie Thomas Postgraduate Medical Research Scholarship (B.J.G.).

P.M.H. and S.K. contributed equally to this work as senior authors.

Disclosures: None declared.
} 
extraintestinal organs. ${ }^{10}$ Bacteremia and endotoxemia are pathologies associated with IBD, ${ }^{20-22}$ whereas intestinal permeability, which would promote passage of bacteria to the serosa, has been associated with dermatologic, musculoskeletal, and hepatic manifestations of IBD. ${ }^{23-25}$ Animal studies suggest that pyrexia associated with bacteremia can promote immune cell mishoming. ${ }^{26}$ Inappropriate immune cell homing is a feature of many EIMs of IBD. In the lung, leukocyte-mediated diseases affecting the central airways, such as bronchiectasis and chronic bronchitis, are the most common EIMs of IBD. ${ }^{27}$ Although these diseases are distinct, they share a similar immunophenotype, characterized by an initial local cytokine secretion and neutrophil recruitment and extravasation into the lungs. ${ }^{28,29}$

Much of our understanding of the pathology of IBD comes from animal models that mimic immune pathologies observed in Crohn disease and ulcerative colitis. For instance, the trinitrobenzenesulfonic acid (TNBS) and dextran sulfate sodium (DSS) murine models of colitis develop systemic inflammation driven by bacteremia and elevated systemic inflammatory cytokines. ${ }^{30,31}$ Although the subclinical nature of pulmonary EIM limits our understanding of the pathology, there is also a lack of basic research modeling the mechanisms of gut-lung cross talk. Given that intestinal permeability and systemic inflammation are characteristic pathologies of animal models of colitis, we hypothesized that subclinical pulmonary pathology would occur in murine models of colitis and thus provide a model to investigate the pathogenesis of colitis-induced respiratory disease. In this study, we aimed to characterize the physiological and immunologic features of colitis-induced respiratory pathologies. Leukocyte populations and cytokine networks present in the pulmonary and circulatory systems of murine models of colitis were examined, and IL-6 was identified as a factor necessary for neutrophilia associated with pulmonary pathology during intestinal inflammation. Furthermore, there was evidence of increased bacterial load and induction of neutrophil chemokines in the lungs of mice with colitis. These data support the hypothesis that EIMs are driven by a combination of increased intestinal permeability and systemic inflammatory signaling and demonstrate that animal models of colitis offer opportunities to study EIMs associated with IBD.

\section{Materials and Methods}

\section{Murine Models of Colitis}

For the DSS model of colitis, 6-week-old female C57BL/6 mice were given $2.5 \%$ DSS ad libitum in drinking water, as previously described. ${ }^{32}$ Age-matched controls received drinking water. Mice received DSS for 5 days and were sacrificed at day 7. For the TNBS colitis model, 6-week-old female BALB/C mice were sensitized by epicutaneous application of $1 \%$ TNBS in acetone/olive oil solution (4:1). After 7 days, mice were anesthetized with isoflurane and intrarectally administered $5 \mu \mathrm{L} / \mathrm{g}$ body weight of a $2.5 \%$
TNBS in 50\% ethanol solution, as previously described. ${ }^{33}$ Control animals received an equivalent volume of $50 \%$ ethanol alone. Core body temperature was measured by infrared thermometer, as previously described. ${ }^{31}$ Mice were sacrificed 7 days after intrarectal TNBS administration. For both models, body weight, fecal occult blood, and stool consistency were recorded daily for each mouse to determine the disease activity index, as described previously. ${ }^{31,34}$ At the experimental end point, the colon, lungs, bone marrow, and blood were collected for analysis.

\section{Anti-IL-6 Treatment Models}

For anti-IL-6 treatments, $200 \mu \mathrm{g}$ of anti-IL-6 (clone MP5-20F3; BioXCell, West Lebanon, NH) was injected intraperitoneally on day 3 and day 5 after initiation of DSS exposure. Rat IgG1 (clone HRPN; BioXCell) was administered as an isotype control.

\section{Histopathological Scoring}

For subsets of experiments, the colon was excised, formalin fixed, embedded in paraffin, and cut longitudinally into sections ( $5 \mu \mathrm{m}$ thick). For lung pathology, lungs were perfused with $0.9 \%$ saline by cardiac puncture with a 19 -gauge needle and fixed by intratracheal inflation with $1.5 \mathrm{~mL}$ of $10 \%$ buffered formalin. The lungs were then excised, formalin fixed, embedded in paraffin, cut longitudinally into sections $(5 \mu \mathrm{m}$ thick). Sections were stained with hematoxylin and eosin for histopathological assessment and were scored by previously validated and published criteria outlined in Table 1 for colon sections $^{33}$ and in Table 2 for lung sections. ${ }^{35,36}$ Structural damage to alveoli and lung parenchyma was calculated using the mean linear intercept method, as previously described. ${ }^{37,38}$

\section{Airway Inflammation Assessment}

Airway inflammation was determined by enumerating leukocytes in the bronchoalveolar lavage fluid (BALF). BALF was collected by intratracheal lavage with phosphate-buffered saline (PBS), as previously described. ${ }^{37}$ The collected fluid was centrifuged $\left(300 \times g, 10\right.$ minutes, $\left.4^{\circ} \mathrm{C}\right)$, and the cell pellet was resuspended in $500 \mu \mathrm{L}$ of red blood cell lysis buffer (Tris-buffer $\mathrm{NH}_{4} \mathrm{CI}$ ) and incubated on ice for 5 minutes. After incubation, the cell suspension was pelleted and resuspended in $250 \mu \mathrm{L}$ of PBS, and viable (trypan blue-negative) leukocytes were enumerated by hemocytometer count.

\section{Cellular Analysis of Lungs, Blood, and Bone Marrow}

Single-cell suspensions were generated from lung tissue, blood, and bone marrow and stained for flow cytometry analysis, as previously described..$^{39}$ Briefly, lung tissue was digested in HEPES buffer containing collagenase D (Sigma-Aldrich, St. Louis, MO) and DNAse for 1 hour at $37^{\circ} \mathrm{C}$, then passed through a $70-\mu \mathrm{m}$ strainer. Cardiac puncture blood was collected in 
Table 1 Gastrointestinal Histopathological Scoring System

\begin{tabular}{ll}
\hline Score 1: inflammation & No evidence for inflammation \\
0 & Low level of inflammation with scattered infiltrating mononuclear cells (1 to 2 foci only) \\
1 & Moderate inflammation with multiple foci \\
2 & High level of inflammation with increased vascular density and marked wall thickening \\
3 & Maximal severity of inflammation with transmural leukocyte infiltration and loss of goblet cells \\
4 & No epithelial injury \\
Score 2: injury & Occasional epithelial lesion \\
0 & 1 to 2 foci of ulcerations \\
1 & Extensive ulcerations \\
2 & \\
3 & on the basis of the properties below, where $0=$ no colitis and $3=$ maximal colitis \\
Score 3: colitis activity & Hypervascularzation \\
Colitis activity scored on a scale of $0-3$ & Presence of mononuclear cells \\
& Epithelial hyperplasia \\
& Epithelial injury \\
Score $4:$ lymphoid aggregates & Presence of neutrophils \\
Total score $=$ (score $1+$ score $2+$ score $3+$ score 4$).$
\end{tabular}

EDTA-coated microvette collection tubes (Sarstedt, Numbrecht, Germany). Bone marrow cells were isolated by flushing femurs with PBS/2\% fetal calf serum. After isolation, red blood cell lysis was performed and cells were enumerated by hemocytometer. After generation of single-cell suspensions, cells were treated with anti-FcrRIII/II Fc block (BD Biosciences, San Jose, CA) and incubated with fixable viability dye eFlour 506 (Ebiosciences, Thermo Fisher Scientific, Waltham, MA) for 20 minutes. The cells were then stained with combinations of fluorochrome-conjugated antibodies, for 45 minutes. Cells were stained to assess myeloid populations [fluorescein isothiocyanate-conjugated CD45, allophycocyanin (APC)conjugated Gr-1, PerCP-Cy5.5-conjugated CD11b, APCCy7-conjugated Ly6C, and phosphatidylethanolamine (PE)-conjugated Siglec-F], lymphoid populations (PECy7-conjugated CD45, PE-conjugated CD3, APC-conjugated CD4, PercP-conjugated CD8a, and fluorescein isothiocyanate-conjugated B220), or progenitor populations (APC-Cy7-conjugated CD45, PE-Cy7-conjugated Sca-1, PerCP-Cy5.5-conjugated c-kit, PE-conjugated CD150, fluorescein isothiocyanate-conjugated CD48, and APCconjugated lineage mixture containing CD3e, CD11b, B220, Ly-76, and Gr-1). All antibodies were supplied by BD Biosciences (San Jose, CA). After antibody incubations, the cells were washed and fixed in $\mathrm{PBS} / 2 \%$ fetal calf serum $/ 0.1 \%$ paraformaldehyde. Cells were analyzed on a BD FACSCanto II flow cytometer, using FACS Diva software version 8.0 (BD Biosciences) or FlowJo version 10.4.1 (BD Biosciences).

\section{Bone Marrow CFU Assays}

Murine bone marrow was obtained by flushing femurs with Dulbecco's modified Eagle's medium supplemented with $2 \%$ fetal calf serum. After red blood cell lysis, a single-cell suspension of bone marrow cells was plated at $2 \times 10^{4}$ cells/ plate in Methocult GF3534 (Stemcell Technologies, Vancouver, BC, Canada). Plates were cultured for 7 days, and myeloid colonies [colony-forming unit (CFU)-granulocyte/ CFU-monocyte/CFU-granulocyte/macrophage] were distinguished and counted by light microscopy on the basis of cell size and colony morphology, in accordance with the manufacturer's instructions. ${ }^{39}$

\section{RNA and Protein Analysis}

RNA analysis was performed by real-time quantitative PCR on a ViiA7 real-time PCR machine (Life Technologies, Waltham,

Table 2 Histopathological Scoring System for Mouse Lungs

\begin{tabular}{ll}
\hline Score & Scoring Criteria \\
\hline Score 1: & airway inflammation \\
0 & Lack of inflammatory cells around airways: absent \\
1 & Some airways have small number of cells: mild \\
2 & Some airways have significant inflammation: moderate \\
3 & Most airways have some inflammation: marked \\
4 & Most airways are significantly inflamed: severe \\
Score 2: vascular inflammation \\
0 & Lack of inflammatory cells around vessels: absent \\
1 & Some vessels have small number of cells: mild \\
2 & Some vessels have significant inflammation: moderate \\
3 & Most vessels have some inflammation: marked \\
4 & Most vessels are significantly inflamed: severe \\
Score $3:$ parenchymal inflammation ( $\times 10$ magnification) \\
0 & $<1 \%$ Affected \\
1 & $1 \%-9 \%$ Affected \\
2 & $10 \%-29 \%$ Affected \\
3 & $30 \%-49 \%$ Affected \\
4 & $>50 \%$ Affected \\
Total score $=($ score $1+$ score $2+$ score 3$)$.
\end{tabular}



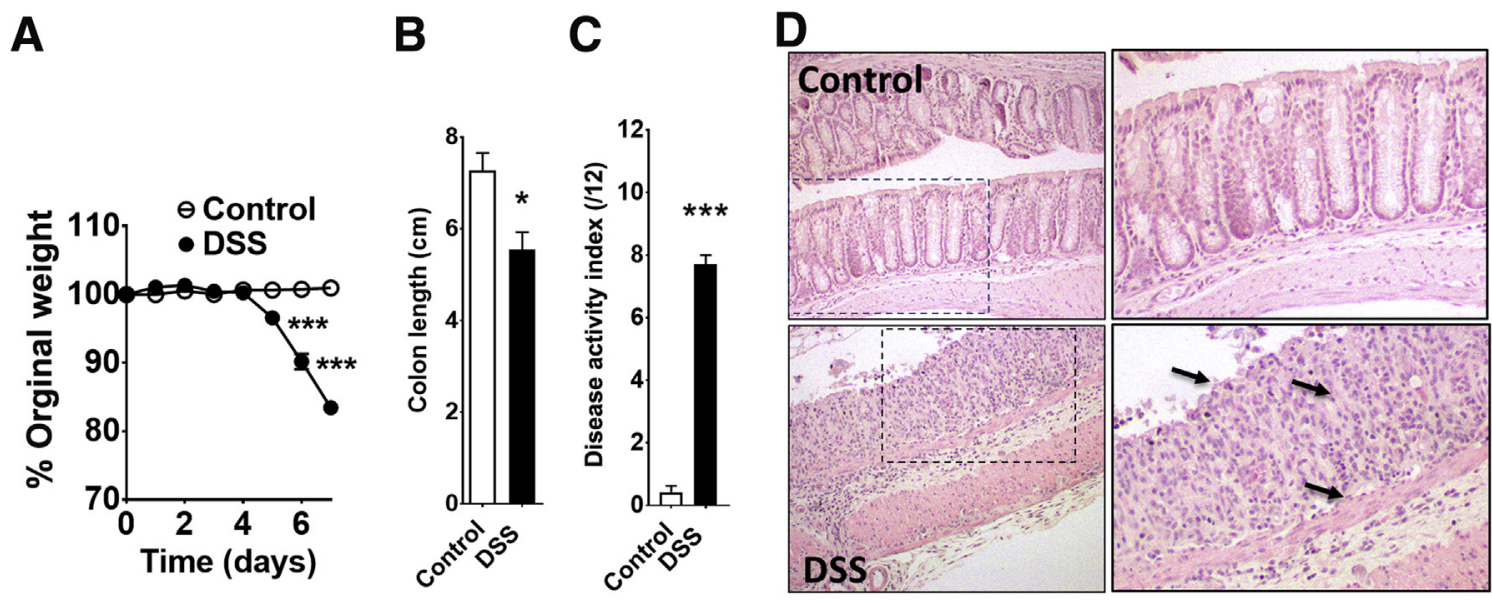

$E$

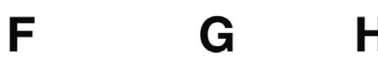

H I
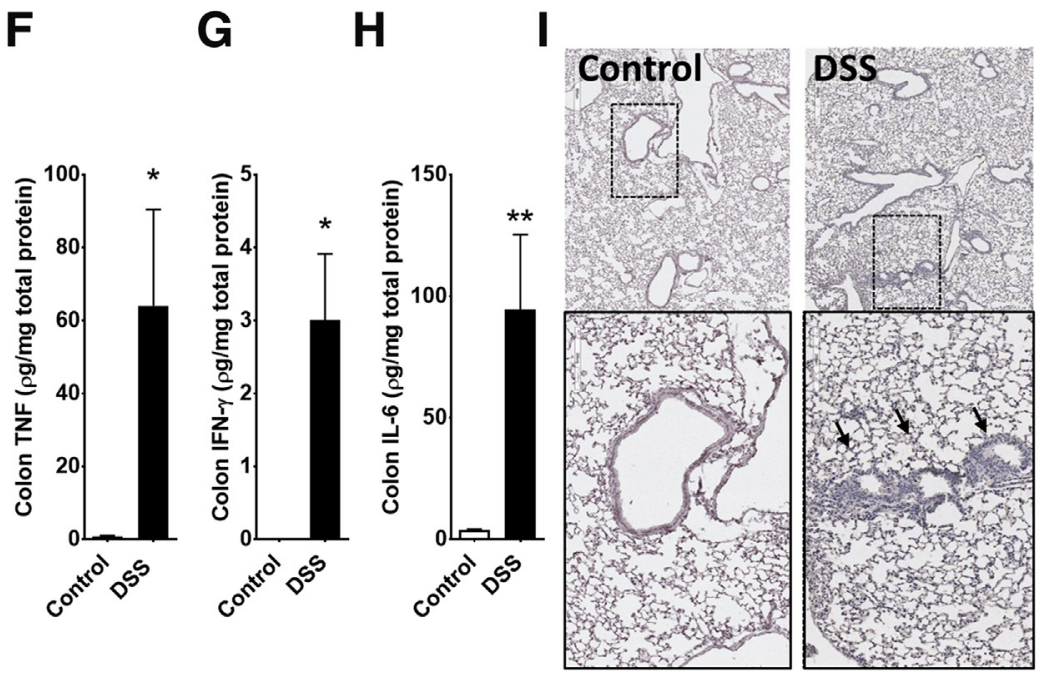

J

$\mathbf{K}$

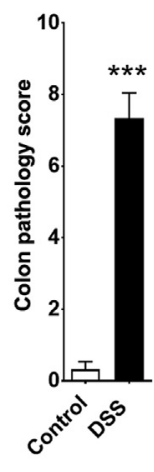

Figure 1 Intestinal and pulmonary pathology in a DSS murine model of colitis. A: Percentage weight loss in DSS animals normalized to controls over the time course of colitis. B: Colon length at experimental end point. C: Disease activity index scores assessed on the basis of stool consistency, occult blood, colon shortening, and weight loss. D: Representative images of colon pathology, with arrows denoting epithelial injury, immune infiltration, and vascular thickening. Boxed areas are shown at higher magnification in the right column (700 $\times 450-\mu \mathrm{m}$ area). E: Histopathology scoring of the extent of disease, as outlined in Table 1. F-H: Inflammatory cytokine levels quantified by cytometric bead array for tumor necrosis factor (TNF)- $\alpha$ (F), interferon (IFN)- $\gamma(\mathbf{G})$, and IL-6 (H) in colon tissue. I: Representative images of pulmonary histopathology, with arrows denoting inflammation. Boxed areas are shown at higher magnification in the bottom row $(900 \times 600-\mu \mathrm{m}$ area). J: Quantitative analysis of lung histopathology. K: The diameter of alveoli in the lungs measured by the mean linear intercept method. L: Airway inflammation determined by enumeration of leukocytes in bronchoalveolar lavage fluid (BALF). Statistical analysis was performed by two-way analysis of variance $(\mathbf{A})$ or unpaired $t$-test $(\mathbf{B}, \mathbf{C}, \mathbf{E}-\mathbf{H}$, and $\mathbf{J}-\mathbf{L}$ ). Data are representative of two pooled experiments. Data are expressed as means $\pm \mathrm{SEM}(\mathbf{B}, \mathbf{C}, \mathbf{E}-\mathbf{H}$, and $\mathbf{J}-\mathbf{L}) . n=6$ to $14(\mathbf{A}-\mathbf{C}, \mathbf{E}-\mathbf{H}$, and $\mathbf{J}-\mathbf{L})$. ${ }^{*} P<0.05,{ }^{* *} P<0.01$, and ${ }^{* * *} P<0.005$ versus control. Original magnification: $\times 20(\mathrm{D}$, left column); $\times 10(\mathrm{D}$, right column, and $\mathbf{I}$, bottom row); $\times 4$ (I, top row).

MA) using SYBR Green reagents (Bio-Rad Laboratories, Hercules, CA). Primers used were as follow: thf, 5'CCCACTCTGACCCCTTTACT-3' (forward) and $3^{\prime}$ TTTGAGTCCTTGATGGTGGT-5' (reverse); ifng, $5^{\prime}-$ TCTTGAAAGACAATCAGGCCATCA-3' (forward) and 3'GAATCAGCAGCGACTCCTTTTCC- $5^{\prime}$ (reverse); and $i l 6,5^{\prime}$ CTACCCCAATTTCCAATGCT-3' (forward) and $3^{\prime}$-ACCACAGTGAGGAATGTCCA-5' (reverse). Primer sets were designed to cross exon boundaries to specifically amplify mRNA products, and expression was normalized to the reference gene $\beta$-actin: $a c t b, 5^{\prime}$-GGAGAAAATCTGGCACCACA-3' (forward) and $3^{\prime}$-AGAGGCGTACAGGGATAGCA-5' (reverse). Tissue and blood protein levels were measured by bicinchoninic acid assay (Pierce Biotechnology, Waltham, MA) and normalized. Colon, lung, and blood were assayed for protein cytokine levels of IL-6, IL-10, chemokine (C-C motif) ligand (CCL) 2 , interferon (IFN)- $\gamma$, and tumor necrosis factor (TNF)- $\alpha$ using the mouse inflammation cytometric bead array kit (BD Biosciences), according to the manufacturer's specifications, analyzed on a BD FACSCanto II flow cytometer, and analyzed using the FCAP array software version 3.0 (BD Biosciences). Keratinocyte chemoattractant (KC; R\&D Systems, Minneapolis, MN) and endotoxin (Lonza, Basel, Switzerland) were measured by enzyme-linked immunosorbent assay. 


\section{Adoptive Transfer of MLN Cell Isolate}

Adoptive transfer of leukocytes was performed by methods adapted from Miyabe et al. ${ }^{40}$ Mesenteric lymph nodes (MLNs) were collected from both control and DSS colitis mice on day 7 after induction of DSS colitis. MLNs were mechanically homogenized, and debris was removed by filtering tissue through a 70- $\mu$ m nylon filter. The total MLN cell suspension was then centrifuged at $187 \times g$ for 10 minutes at $4^{\circ} \mathrm{C}$ and resuspended at a concentration of $1 \times 10^{7}$ cells $/ \mathrm{mL}$ in PBS with $5 \mu \mathrm{mol} / \mathrm{L}$ of carboxyfluorescein succinimidyl ester (CFSE; 5 minutes at room temperature). Cells were collected by centrifugation, washed in Hanks' balanced salt solution, resuspended in $1 \mathrm{~mL}$ of PBS, and counted. Cell suspensions were diluted, and $100 \mu \mathrm{L}\left(1 \times 10^{6}\right.$ cells $)$ was injected intravenously into control and DSS colitis - treated mice (day 7 after induction). Twentyfour hours after injection, mice were sacrificed and the lungs were collected for analysis by flow cytometry.

\section{Statistical Analysis}

Comparisons between two groups were made using unpaired $t$ tests. Comparisons between multiple groups were made using a one-way analysis of variance. For analysis of data with two independent variables (such as weight loss data), a two-way analysis of variance was used. Correlations were analyzed by Pearson coefficient. Analyses were performed using GraphPad Prism Software version 7.0 (GraphPad, San Diego, CA).

\section{Results}

\section{Pulmonary Inflammation 0ccurs in Murine Colitis}

Initially, it was examined whether structural or biochemical changes in the lung were associated with murine models of colitis. An acute 7-day model of DSS colitis was used. This model exhibited characteristic weight loss [means \pm SD $(\%$ original weight): control, $101.51 \pm 2.881$; DSS, $83.44 \pm 3.96$; $P<0.0001$ ] (Figure 1A) and colon shortening [means \pm SD (cm): control, $7.28 \pm 0.84$; DSS, $5.54 \pm 0.87 ; P=0.012]$ (Figure 1B) and increased disease activity index scores [means \pm SD (arbitrary units): control, $0.43 \pm 0.20$; DSS, $7.71 \pm 0.29 ; P<0.0001$ ] (Figure 1C) compared with control mice. Structural pathology, as measured by histopathology scoring of hematoxylin and eosin sections (Figure 1D), was significantly higher in DSS mice compared with controls [means \pm SD (arbitrary units): control, $0.34 \pm 0.51$; DSS, $7.34 \pm 1.75 ; P<0.005]$ (Figure 1E). Levels of TNF- $\alpha$ (Figure 1F), IFN- $\gamma$ (Figure 1G), and IL-6 (Figure 1H) inflammatory cytokines were quantified in colon tissue, because these cytokines are up-regulated in colonic biopsy specimens from IBD patients and are acknowledged to contribute to disease pathology and progression. ${ }^{41}$ The protein levels of TNF- $\alpha$ [means \pm SD (pg/mL): control, $0.77 \pm 0.79$; DSS, $64.08 \pm 64.51 ; P=0.0371]$, IFN- $\gamma$ [means $\pm \mathrm{SD}(\mathrm{pg} / \mathrm{mL})$ : control, $0.0001 \pm 0.0001 ; \mathrm{DSS}, 3.01 \pm 2.22 ; P=0.0436]$, and
IL-6 [means $\pm \mathrm{SD}(\mathrm{pg} / \mathrm{mL})$ : control, $3.86 \pm 0.81$; DSS, $94.50 \pm 75.43 ; P=0.0147]$ were significantly increased in colon tissue from DSS colitis mice compared with healthy controls.

Having confirmed intestinal pathology, the airways were examined for associated pulmonary manifestations of DSS colitis. Histopathology was quantified on the basis of leukocyte congregation around the airway vasculature and parenchyma using a previously validated scoring ${ }^{35}$ of hematoxylin and eosin-stained lung sections (Figure 1I). A significant increase in histopathological scores was observed in the lungs of DSS colitis animals [means \pm SD (arbitrary units): control, $0.60 \pm 0.55$; DSS, $3.0 \pm 1.87 ; P=0.0249$ ] (Figure 1J), with most inflammation localized around the pulmonary vasculature. To examine whether the vascular inflammation influenced lung morphology, alveoli diameter was calculated using the mean linear intercept method; however, there was no change in alveoli diameter between control and DSS colitis animals (Figure 1K). Given the histologic evidence of immune infiltration, BALF was assessed for increases in leukocytes (Figure 1L), and increased BALF cell numbers were found in DSS animals, compared with controls [means \pm SD (cells/ $\mathrm{mL})$ : control, $35.45 \times 10^{4} \pm 17.06 \times 10^{4} ;$ DSS, $51.49 \times 10^{4} \pm$ $\left.14.26 \times 10^{4} ; P<0.035\right]$.

To examine whether colitis-associated pulmonary pathology was a feature specific to the DSS model of colitis, the analysis was extended into the TNBS model of colitis. TNBS colitis led to early significant weight loss (Figure 2A), and disease activity [means \pm SD (arbitrary units): control, $1.50 \pm 0.55$; TNBS, $5.17 \pm 1.47 ; P=0.0002$ ] (Figure $2 \mathrm{~B}$ ) remained significantly increased in TNBS-treated animals on day 7, when compared with ethanol-treated control groups. Colonic inflammation was also evident in TNBS-treated animals on day 7 (Figure 2C), and histopathology scoring showed a significant increase in inflammatory pathology when compared with ethanol-treated controls [means $\pm \mathrm{SD}$ (arbitrary units): control, $0.67 \pm 0.52$; TNBS, $5.34 \pm 1.21 ; P<0.0001]$ (Figure 2D). On histopathological examination of lung pathology in the TNBS colitis model (Figure 2E), significant increases in pulmonary pathology were observed by pathology scoring [means $\pm \mathrm{SD}$ (arbitrary units): control, $0.84 \pm 0.75$; TNBS, $2.50 \pm 1.05 ; P=0.01]$ (Figure 2F), consistent with findings in the DSS model. Also consistent with findings in the DSS model, increased leukocyte cell numbers were found in the BALF of TNBS animals, compared with controls (Figure 2G) [means $\pm \mathrm{SD}$ (cells $/ \mathrm{mL}$ ): control, $15.43 \times 10^{4} \pm 7.58 \times 10^{4}$; TNBS, $28.63 \times 10^{4} \pm 11.69$ $\left.\times 10^{4} ; P<0.0179\right]$. Together, these data demonstrate that leukocyte recruitment to the airway is a feature of animal models of colitis.

Myeloid, but Not Lymphoid, Cells Are Recruited to the Lung in Acute Colitis Models

The phenotype of leukocytes was next observed in the lungs in murine colitis models. Flow cytometry staining panels were designed to allow quantification (Figure 3A) 


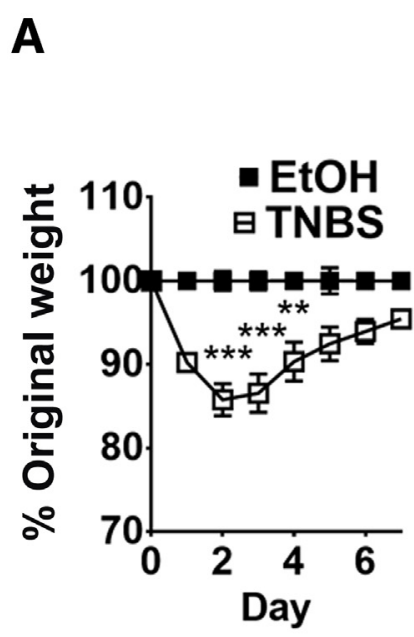

D

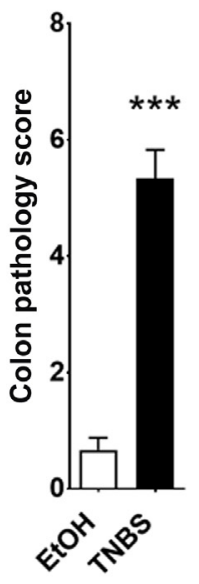

B

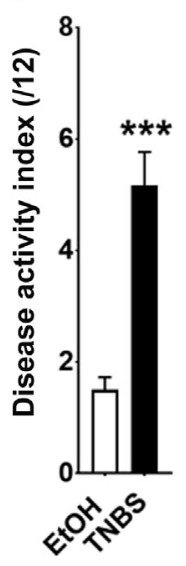

E

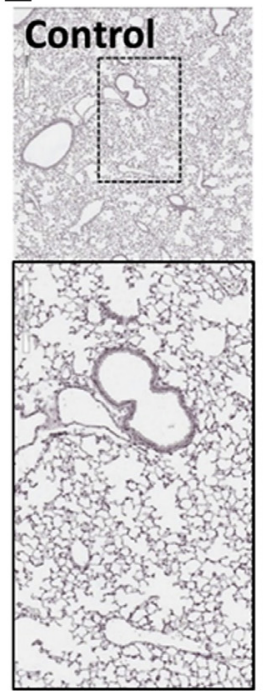

C

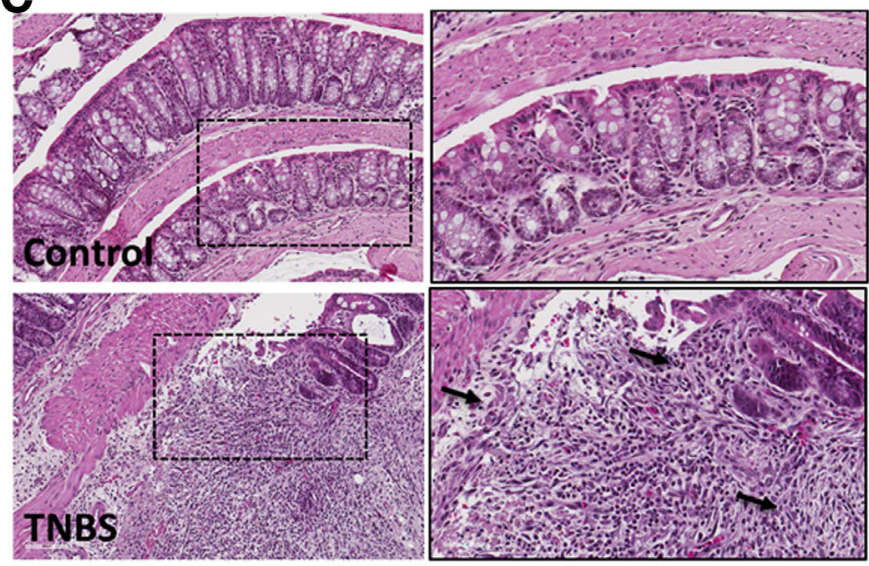

$\mathbf{F}$

G

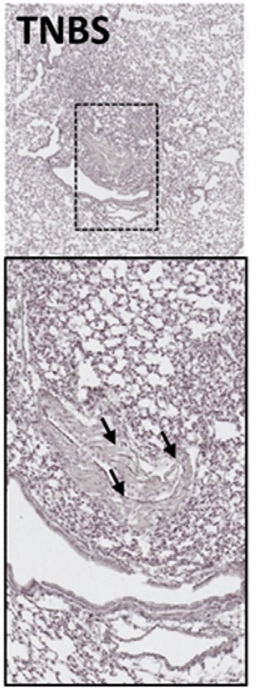

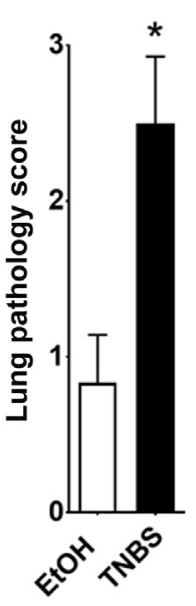

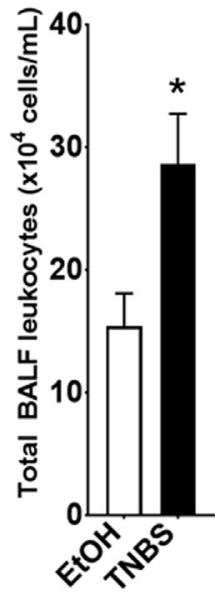

Figure 2 Intestinal and pulmonary pathology in a trinitrobenzenesulfonic acid (TNBS) murine model of colitis. A: Percentage weight loss in TNBS animals normalized to controls during the time course of colitis. B: Disease activity index scores assessed from stool consistency, occult blood, colon shortening, and weight loss. C: Representative images of colon pathology, with arrows denoting epithelial injury and immune infiltration. Boxed areas are shown at higher magnification in the right column $(670 \times 400-\mu \mathrm{m}$ area). D: Histopathology scoring of the extent of disease. E: Representative images of the pulmonary histopathology; arrows denote inflammation. Boxed areas are shown at higher magnification in the bottom row $(1000 \times 680-\mu \mathrm{m}$ area). F: Quantitative analysis of lung histopathology. G: Airway inflammation determined by enumeration of leukocytes in bronchoalveolar lavage fluid (BALF). Statistical analysis was performed with two-way analysis of variance $(\mathbf{A})$ or unpaired $t$-test $(\mathbf{B}, \mathbf{D}, \mathbf{F}$, and $\mathbf{G})$. Data are representative of two pooled experiments. Data are expressed as means $\pm \operatorname{SEM}(\mathbf{A}, \mathbf{B}, \mathbf{D}, \mathbf{F}$, and $\mathbf{G}) . n=6(\mathbf{E}) ; n=8$ to $14(\mathbf{A}-\mathbf{D}, \mathbf{F}$, and $\mathbf{G}) .{ }^{*} P<0.05,{ }^{* *} P<0.01$, and ${ }^{* * *} P<0.005$ versus control. Original magnification: $\times 20$ (C, left column); $\times 10(C$, right column, and $E$, bottom row); $\times 4$ (E, top row). EtOH, ethanol.

of myeloid cell populations. A significant increase in the percentage of neutrophils [means $\pm \mathrm{SD}(\%)$ : control, $7.35 \pm 1.65 ;$ DSS, $12.63 \pm 1.95 ; P<0.001]$ and inflammatory monocytes [means $\pm \mathrm{SD}(\%)$ : control, $3.68 \pm 0.63$; DSS, $7.72 \pm 1.14 ; P<0.0028]$ in the lung of DSS colitis mice was observed (Figure 3B). These increases were also evident when comparing cell numbers [means \pm SD (cell numbers): neutrophils: control, $1.57 \times$ $10^{5} \pm 0.65 \times 10^{5} ;$ DSS, $3.49 \times 10^{5} \pm 1.19 \times 10^{5}$; $P<0.0058$; inflammatory monocytes: control, $0.76 \times 10^{5}$ $\pm 0.24 \times 10^{5} ;$ DSS, $2.18 \times 10^{5} \pm 0.85 \times 10^{5}$; $P<0.0028]$. Resident monocyte and eosinophil numbers were not altered between groups. Similarly, in TNBS animals, neutrophil populations were increased [means \pm SD (\%): control, $12.21 \pm 2.96$; TNBS, $20.27 \pm 2.11 ; P=0.006]$, but in contrast to DSS animals, there was no significant change in either inflammatory or tissue lung monocyte populations compared with healthy controls (Figure 3C). No change was observed in lymphocyte populations in the lungs of DSS (Figure 3D) or TNBS (Figure 3E) mice, compared with controls. These data indicate increases in predominantly neutrophil leukocyte populations entering the lungs of animals during colitis. 
A

\section{Control}

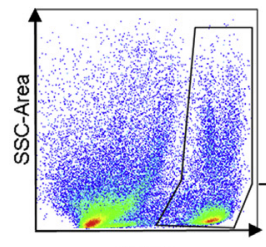

$\mathrm{CD} 45$
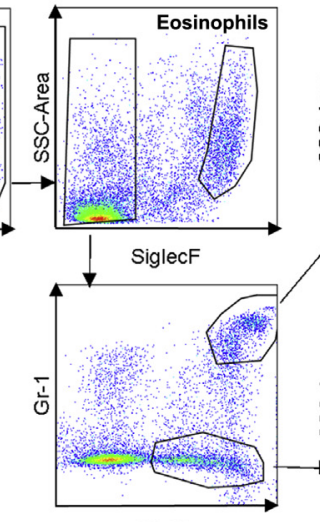

CD11b

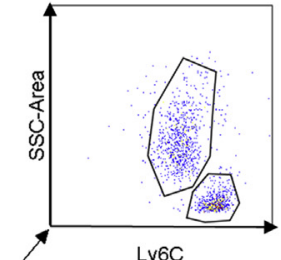

เу6C

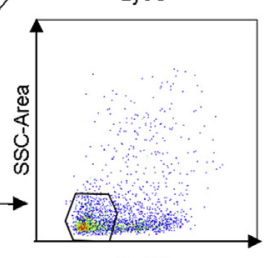

Ly6C

\section{DSS}

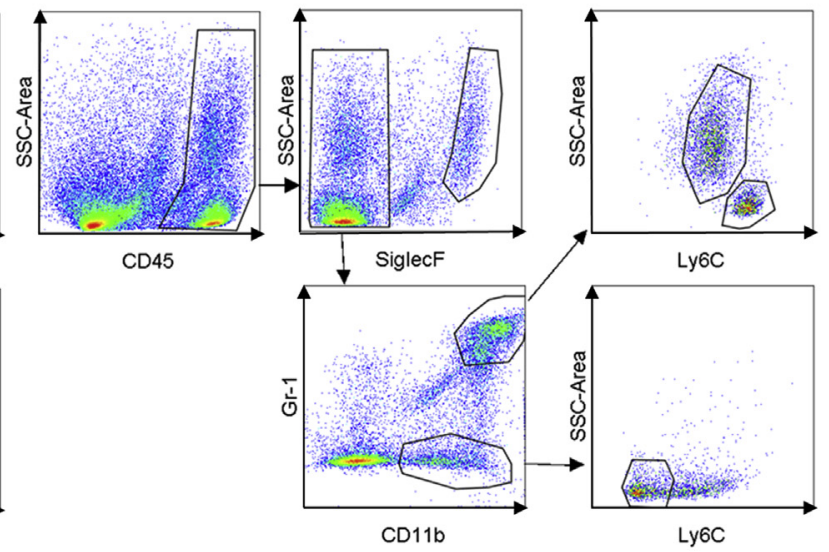

B

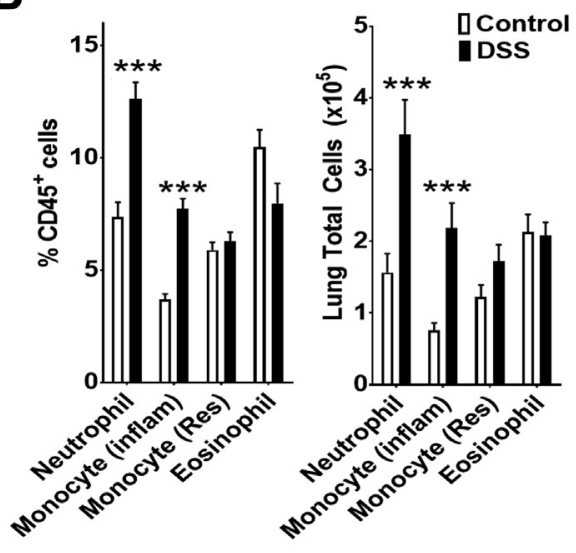

C

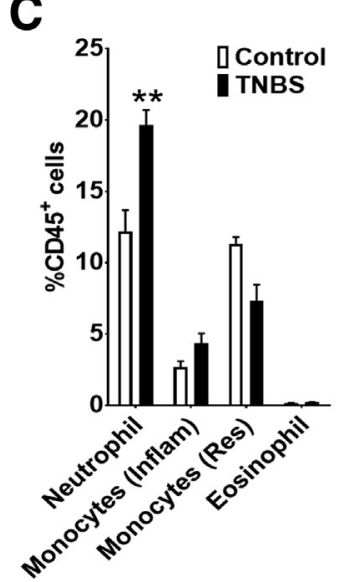

D

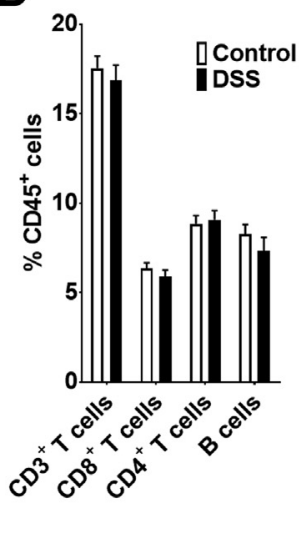

E

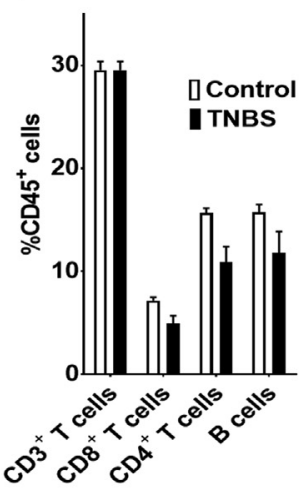

Figure 3 Immune cell populations in the lungs of control and DSS colitis mice. A: Representative gating strategy for the identification of leukocytes in lungs. Hematopoietic cells were identified as $\mathrm{CD}_{4} 5^{+}$cells and eosinophils $\left(\right.$SiglecF $F^{+}$), and neutrophils $\left(\mathrm{Gr}-1^{+} \mathrm{CD} 11 \mathrm{~b}^{+} \mathrm{Ly}_{\mathrm{C}} \mathrm{C}^{\text {int }} \mathrm{SSC} \mathrm{C}^{\text {int }}\right)$, inflammatory $(\mathrm{Inflam})$ monocytes $\left(\mathrm{Gr}-1^{+} \mathrm{CD} 11 \mathrm{~b}^{+} \mathrm{Ly} 6 \mathrm{C}^{\text {hi }} \mathrm{SSC}{ }^{\mathrm{lo}}\right)$, and tissue resident (Res) monocytes $\left(\mathrm{Gr}-\mathrm{1}^{\mathrm{lo}} \mathrm{CD} 11 \mathrm{~b}+\mathrm{Ly} 6 \mathrm{C}^{\mathrm{lo}} \mathrm{SSC} \mathrm{C}^{\mathrm{lo}}\right)$ were quantified by flow cytometry. B: The proportion (\% CD45 cells) and total number of myeloid cells in the lung. C: The proportion of myeloid cells in the lung of trinitrobenzenesulfonic acid (TNBS) colitis mice. D and E: The proportion of lymphoid cells in the lungs of DSS colitis mice (D) and TNBS colitis mice (E), represented as $\%$ CD45 cells. Two separate experiments were conducted. Data are expressed as means \pm SEM (B-E). $n=6(\mathbf{B}-\mathbf{E}) .{ }^{* *} P<0.01,{ }^{* * *} P<0.005$ verus control (unpaired $t$-test). SSC, side scatter.

\section{Colitis-Driven Bacteremia Drives Pulmonary Inflammation}

Having identified increases in the proportion of neutrophils in the lungs of DSS colitis animals, it was next examined whether neutrophil recruitment to the lungs was an active or passive phenomenon. An adoptive transfer of CFSE-stained MLN cells was performed from healthy and DSS animals into healthy or DSS recipient animals, and cell populations homing to the lungs of recipient animals were evaluated (Figure 4A). A total of $1 \times 10^{6}$ unsorted MLN cells were transferred from control or DSS-treated animals. Within the transferred cell population, this represents 40,080 $\pm 18,730$ neutrophils from control MLNs and 48,050 $\pm 21,314$ neutrophils transferred from MLNs isolated from DSS-treated mice. There was no significant increase in the percentages of CFSE-stained neutrophils in the lungs of either DSS donor to healthy recipient mice [means \pm SD (\% transferred cells): $0.3505 \pm 0.1283$ ] or healthy donor to DSS recipient mice [means \pm SD (cells): $0.3246 \pm 0.1748$ ], when compared with healthy to healthy transfers [means \pm SD (cells): $0.1313 \pm 0.0725]$. However, there were significantly higher percentages of CFSE-stained neutrophils in the lungs of animals for the DSS donor to DSS recipient groups [means \pm SD (cells): $1.613 \pm 0.5479$; $P<0.0001]$ compared with all other groups. There were no differences in the numbers of other CFSE-stained myeloid or lymphoid cell populations. Together, these data suggest that increased homing of neutrophils to the lung requires both local lung and systemic factors.

Local mediators of airway inflammation in DSS colitis were next investigated. Gene expression analysis showed significant increases in tnfa [means $\pm \mathrm{SD}$ (fold change): control, $1.1 \pm 0.53$; DSS, $7.60 \pm 4.49 ; P=0.028$ ], ifng [means $\pm \mathrm{SD}$ 
A

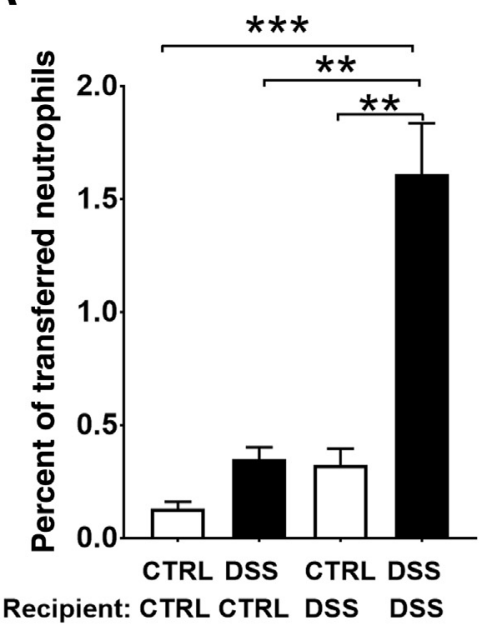

B

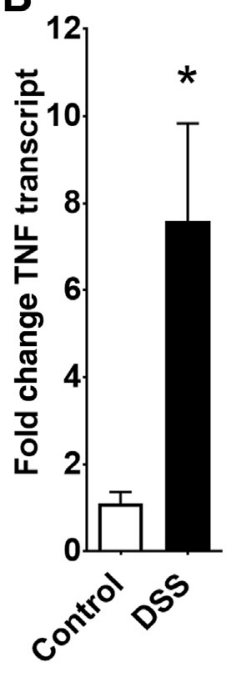

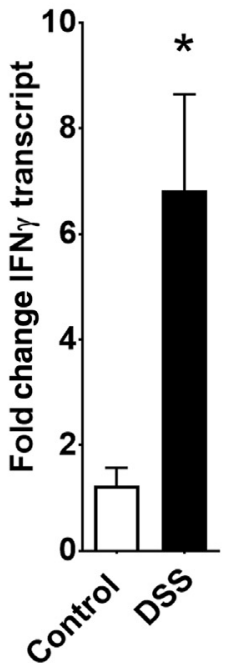
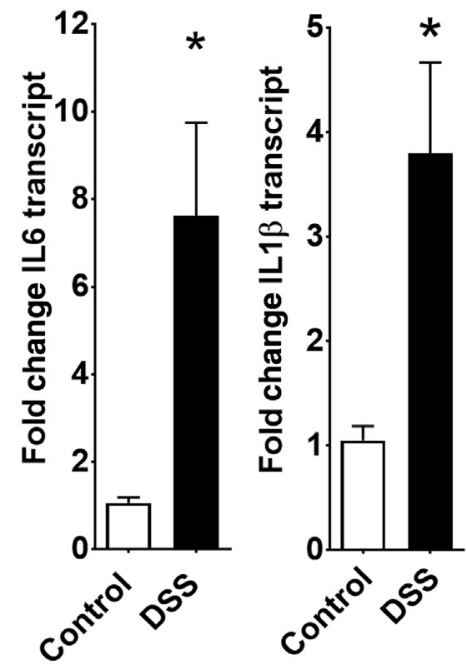

C

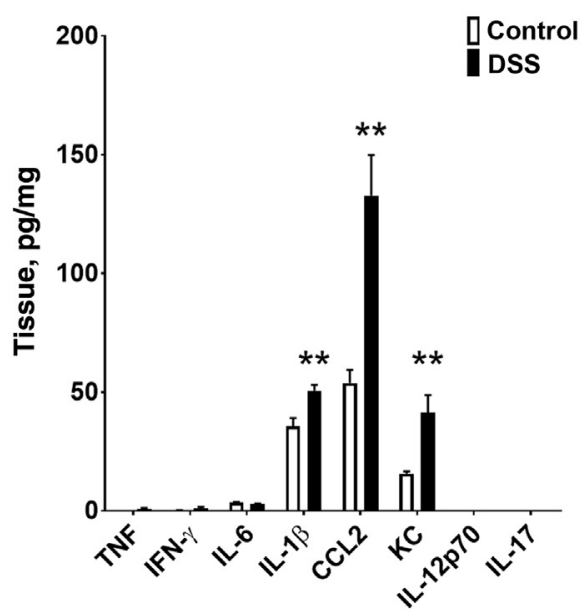

D

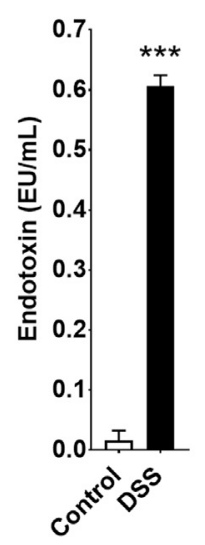

E

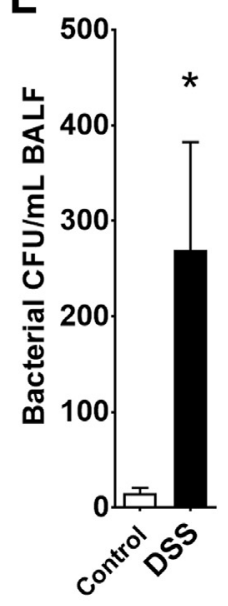

Figure 4 Airway inflammation in DSS colitis mice. A: Carboxyfluorescein succinimidyl ester (CFSE)-stained cells harvested from the mesenteric lymph nodes of control (CTRL) and DSS mice were injected into either naïve control or DSS colitis recipient mice. The percentage of total transferred neutrophils (CFSE ${ }^{+} \mathrm{Gr}-1^{+} \mathrm{CD}_{11 b^{+}}$Ly6 $\mathrm{C}^{\text {int }} \mathrm{SSC} \mathrm{C}^{\text {int }}$ ) in the lung was calculated 24 hours after transfer. B-E: Gene expression analysis of tumor necrosis factor (TNF)- $\alpha$, interferon (IFN)- $\gamma$, IL-6, and IL-1 $\beta$ (B) and proteins levels of TNF- $\alpha$, IFN- $\gamma$, IL-6, IL-1 $\beta$, chemokine (C-C motif) ligand (CCL) 2, keratinocyte chemoattractant, IL-12p70, and IL-17 (C) measured in the lung. Endotoxin levels (D) and cultured bacterial colony-forming units (E) from the lungs of control and DSS animals. Statistical analysis was performed by one-way analysis of variance $(\mathbf{A})$ or unpaired $t$-test $(\mathbf{B}-\mathbf{E})$. Data are expressed as means \pm SEM. $n=6$. ${ }^{*} P<0.05$, ${ }^{* * P}<0.01$, and ${ }^{* * * P}<0.005$ versus control. BALF, bronchoalveolar lavage fluid.

(fold change): control, $1.23 \pm 0.97$; DSS, $6.83 \pm 5.5$; $P=0.012$ ], il6 [means $\pm \mathrm{SD}$ (fold change): control, $1.06 \pm 0.35 ;$ DSS, $7.62 \pm 6.38 ; P=0.011]$, and $i l 1 \beta$ [means \pm SD (fold change): control, $1.05 \pm 0.38$; DSS, $3.80 \pm 2.74 ; P=0.013$ ] expression in the lungs of the DSS model compared with healthy controls (Figure 4B). However, protein analysis of these cytokines showed increases in IL-1 $\beta$ alone [means $\pm \mathrm{SD}(\mathrm{pg} / \mathrm{mL})$ : control, $35.70 \pm 5.92$; DSS, $50.66 \pm 5.90 ; P=0.024]$, with no significant increases in TNF- $\alpha$, IFN- $\gamma$, or IL-6 protein levels (Figure 4C). Further assessment of inflammatory mediators identified a significant increase in both CCL2 [means $\pm \mathrm{SD}(\mathrm{pg} / \mathrm{mL})$ : control, $53.84 \pm 5.541 ;$ DSS, $132.9 \pm 17.01 ; P=0.0013]$ and $\mathrm{KC}$ [means $\pm \mathrm{SD}(\mathrm{pg} / \mathrm{mL})$ : control, $15.67 \pm 2.66$; DSS, $41.50 \pm 17.69 ; P=0.0054$ ] protein levels in the lungs of DSS mice (Figure 4C), but no changes in protein levels of IL-12p40 or IL-17. As we have previously shown bacteremia in animal models of colitis and because CCL2 and $\mathrm{KC}$ are proinflammatory mediators during pulmonary inflammation induced by bacterial cell wall components, ${ }^{42}$ endotoxin levels were assessed in the lung tissue of DSS mice, compared with controls (Figure 4D). DSS mice exhibited a 37-fold increase in lung endotoxin [means $\pm \mathrm{SD}$ (EU/mL): control, $0.016 \pm 0.03$; DSS, $0.606 \pm 0.036 ; P<0.0001]$. Given this increase, microbial culture was next performed on BALF from control and DSS animals and an 18-fold increase was found in bacterial colonyforming units in the BALF of DSS animals, when compared with controls (Figure 4E) [means $\pm \mathrm{SD}(\mathrm{CFU} / \mathrm{mL})$ : control, $15.17 \pm 13.66$; DSS, $269.3 \pm 276.7 ; P=0.0484]$. Taken together, these data demonstrate that an increased bacterial load 


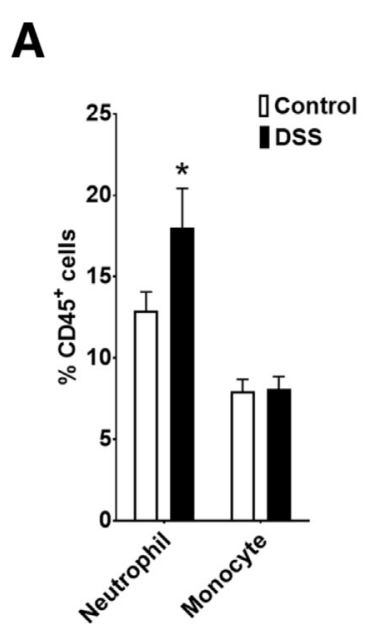

B

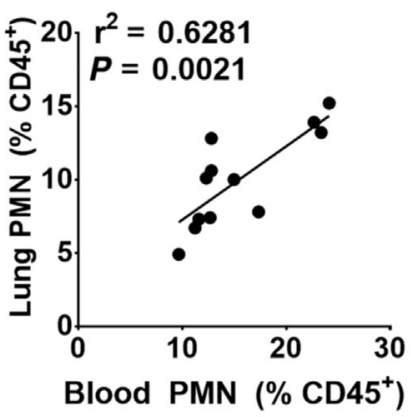

E

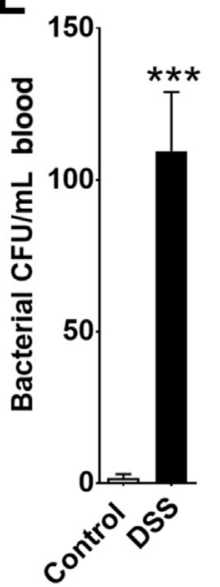

F

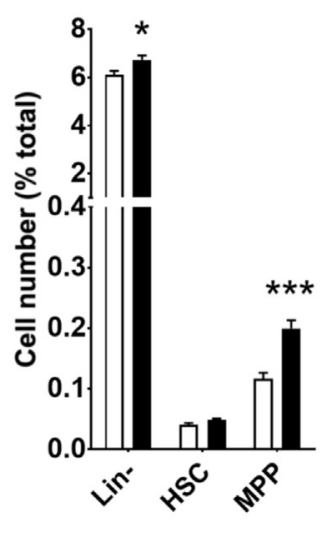

C

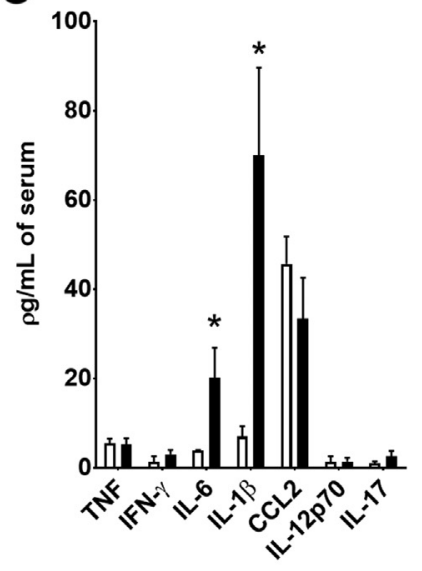

D

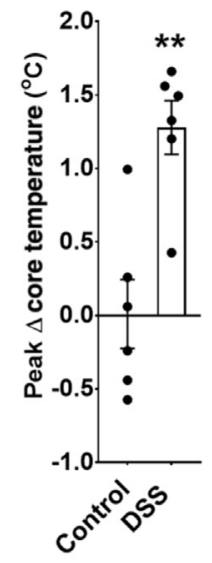

H

G

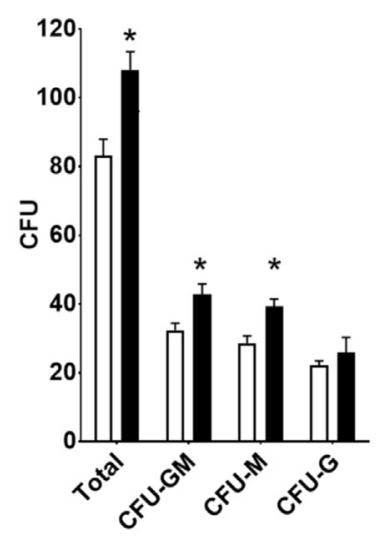

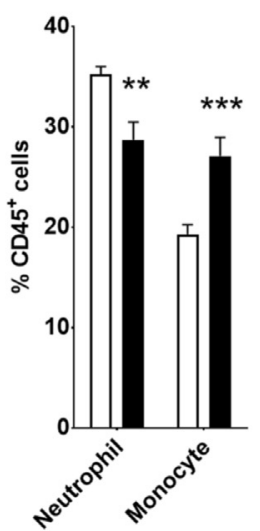

Figure 5 Systemic inflammation in DSS colitis. A: The proportion of neutrophils and monocytes in the blood of DSS colitis mice, compared with controls, represented as $\% \mathrm{CD} 45^{+}$cells. B: A correlation between the number of neutrophils in the blood and the lung neutrophil numbers quantified by flow cytometry. C: Systemic cytokines tumor necrosis factor (TNF)- $\alpha$, interferon (IFN)- $\gamma$, IL-6, IL-1 $\beta$, chemokine (C-C motif) ligand (CCL) 2, keratinocyte chemoattractant, IL12p70, and IL-17 in serum measured by enzyme-linked immunosorbent assay (IL-1 $\beta$ and keratinocyte chemoattractant) and cytometric bead array. D: Mean peak body temperature, measured by infrared thermometer over 7-day course of DSS model. E: Bacterial colony-forming units (CFUs) cultured from whole blood of control and DSS animals. F: Proportion of lineage-negative cells (Lin $\left.{ }^{-}\right)$, hematopoietic stem cells (HSCs; Lin $\left.^{-} \mathrm{CD}_{48}{ }^{-} \mathrm{CD} 150^{+}\right)$, and multipotent progenitor stem (MPP; Lin ${ }^{-} \mathrm{CD} 48^{+} \mathrm{CD} 150^{-}$) cells in the bone marrow, measured by flow cytometry. G: The number of granulocyte (CFU-G), macrophage (CFU-M), and granulocyte/macrophage (CFU-GM) colony-forming units in bone marrow. H: The proportion of mature neutrophils and monocytes in the bone marrow, measured by flow cytometry. Statistical analysis was performed by unpaired $t$-test $(\mathbf{A}$ and $\mathbf{C}-\mathbf{H})$ or Pearson correlation (B). Data are expressed as means $\pm \mathrm{SEM}$. $n=6$ from two separate experiments. ${ }^{*} P<0.05,{ }^{*} P<0.01$, and ${ }^{*} * P<0.005$ versus control. PMN, polymorphonuclear leukocyte.

in the lungs of DSS animals is associated with increased inflammatory and chemotactic signaling molecules, which may drive recruitment of inflammatory cells during colitis.

\section{Neutrophilia Underpins the Systemic Inflammation in DSS Colitis}

Because leukocytes use the circulatory system to enter and exit tissues of interest, the effect of colitis on systemic inflammation was next examined, and it was determined whether there is a relationship between the systemic and pulmonary inflammation induced by DSS colitis. Mice with DSS colitis exhibited significantly higher proportions of circulating neutrophils compared with control animals [means \pm SD (\%): control, $12.91 \pm 2.8$; DSS, $18.01 \pm 5.91 ; P<0.05]$ (Figure 5A), but in contrast to the lung tissue of DSS animals, there was no change in the proportion of monocytes. Furthermore, a significant correlation was identified between the percentage of neutrophils in the blood and the percentage of neutrophils in the lung (Pearson $r^{2}$ value $=0.628, P=0.0021$ ) (Figure 5B), suggesting a possible relationship between systemic and pulmonary neutrophilia in DSS colitis mice. Given the correlation between lung and blood neutrophils, it was investigated whether the same trends existed with serum cytokine levels. Significant increases were found in systemic IL-6 [means \pm SD $(\mathrm{pg} / \mathrm{mL})$ : control, $3.89 \pm 0.34 ;$ DSS, $20.16 \pm 16.57$; $P<0.037$ ], IL- $1 \beta$ [means $\pm \mathrm{SD}(\mathrm{pg} / \mathrm{mL})$ : control, $7.03 \pm 5.62$; DSS, $69.99 \pm 39.32 ; P=0.023$ ], and KC [means $\pm \mathrm{SD}(\mathrm{pg} /$ $\mathrm{mL})$ : control, $1.45 \pm 0.88$; DSS, $10.68 \pm 7.16 ; P=0.043]$, but not TNF- $\alpha$, IFN- $\gamma$, CCL2, IL-12p70, or IL-17 (Figure 5C), 
indicating that systemic inflammation is not a consequence of cytokine spillover into the circulation from either intestinal or pulmonary inflammation. Because systemic IL-6 is associated with pyrexia in animal models of colitis and because of the increased levels of bacteria and endotoxin observed in the lungs of DSS animals, core body temperature (as an indicator of a hyperthermic response) was next investigated. DSS animals had a significantly higher peak body temperature during the course of disease, when compared with controls [means \pm SD $\left(\Delta^{\circ} \mathrm{C}\right)$ : control, $0.01 \pm 0.57$; DSS, $\left.1.28 \pm 0.45 ; P=0.0016\right]$ (Figure 5D), suggesting the DSS model of colitis is associated with a pyrexic response. To verify the presence of circulating bacteria that drive pyrexia, $\mathrm{CFU}$ was cultured from the blood of control and DSS animals and a 66-fold increase in bacterial colony-forming units was found in the blood of DSS animals, when compared with controls [means $\pm \mathrm{SD}$ (CFU/mL): control, $1.67 \pm 3.20 ;$ DSS, $109.5 \pm 47.69 ; P=0.0003$ ] (Figure 5E). This supports the hypothesis that systemic bacteremia (potentially attributable to loss of barrier function) leads to an increased burden in the lung and drives pulmonary inflammation.

\section{Myeloid Hematopoiesis Is Increased in DSS Colitis}

Given the proportional increase in neutrophils in both the circulatory and pulmonary systems with intestinal inflammation, the influence of intestinal inflammation was also characterized on myeloid cell progenitor populations in the bone marrow during DSS colitis. DSS mice had a small, but significant, increase in bone marrow lineage-negative cells [means \pm SD (\%): control, $6.11 \pm 0.39$; DSS, $6.73 \pm 0.46$; $P=0.032$ ] (Figure 5F). This increase was attributed to an increase in multipotent progenitor cells $\left(\mathrm{CD} 48^{+} \mathrm{CD} 150^{-}\right)$ [means \pm SD (\%): control, $0.116 \pm 0.026 ;$ DSS, $0.1995 \pm 0.034 ; P<0.001$ ], with no change in hematopoietic stem cells $\left(\mathrm{CD} 48^{-} \mathrm{CD} 150^{+}\right)$. Bone marrow $\mathrm{CFU}$ assays were also performed to functionally quantify myeloid progenitor cell numbers. Bone marrow from DSS had significantly higher total $\mathrm{CFUs}\left(\mathrm{CD} 48^{+} \mathrm{CD} 150^{+}\right)$than control animals (means \pm SD: control, $83.25 \pm 9.39$; DSS, $108.13 \pm 10.54 ; P=0.0125$ ), which was attributed to increases in granulocyte/monocyte CFUs (means \pm SD: control, $32.38 \pm 4.15$; DSS, $42.88 \pm 5.94 ; P=0.027)$ and monocyte CFUs (means \pm SD: control, $28.63 \pm 4.31$; DSS, $39.25 \pm 4.37 ; P=0.013$ ) populations but not granulocyte CFUs (Figure $5 \mathrm{G}$ ). Cellular analysis of the proportion of mature myeloid cells in the bone marrow revealed a significant decrease in the proportion of neutrophils [means \pm SD (\%): control, $35.28 \pm 1.80$; DSS, $28.71 \pm 4.34 ; P=0.0065]$ and an increase in the proportion of monocytes [means $\pm \mathrm{SD}(\%)$ : control, $19.30 \pm 2.33$; DSS, $27.10 \pm 4.53 ; P=0.0038$ ] (Figure 5H). These results indicate that myeloid cell production is increased in bone marrow during DSS colitis and may indicate a rapid egress of neutrophils from the bone marrow niche to the circulatory system.
IL-6 Is Critical for Pulmonary Neutrophilia in DSS Colitis

Given the predominance of neutrophils in the lung and circulatory system of DSS animals and the increases in systemic IL-6, which can drive neutrophil mobilization, it was next investigated whether IL-6 neutralization after the induction of colitis influenced the neutrophilia observed in DSS colitis. Serum levels of IL-6 were measured by cytometric bead array assay and were significantly reduced in anti-IL-6-treated animals compared with other groups [means $\pm \mathrm{SD}(\mathrm{pg} / \mathrm{mL})$ : control, $0.78 \pm 0.65$; DSS (naïve), $19.33 \pm 8.24$; DSS (isotype), $16.27 \pm 7.95$; DSS (anti-IL-6), $4.07 \pm 0.93]$ (Figure 6A). DSS mice treated with anti-IL-6 lost significantly less weight compared with DSS mice treated with isotype controls or with untreated DSS mice [means \pm SD (\% original weight): DSS (isotype), $79.34 \pm 1.59$; DSS (anti-IL-6), $86.50 \pm 4.96 ; P<0.0001 ;$ DSS (untreated), $78.74 \pm 2.14 ; P<0.0001$ ] (Figure 6B). However, no change in colon shortening (Figure 6C), disease activity index (Figure 6D), or histopathology score (Figure 6, E and F) was observed between the naïve DSS, anti-IL-6, and isotype groups, suggesting that IL- 6 is important in systemic responses during colitis but for maintaining local GI inflammation. In agreement with this, there was no change in the protein levels of inflammatory cytokines TNF- $\alpha, \mathrm{IFN}-\gamma$, or CCL2 in the colon between the DSS isotype controls and DSS anti-IL-6-treated mice (Figure 6G).

Cellular analysis of the lungs of anti-IL-6-treated mice was next performed to assess whether neutralization of IL-6 reduced colitis-induced pulmonary immunopathology. Anti-IL-6-treated DSS mice exhibited significant decreases in both the proportion and total number of lung neutrophils compared with both the isotype-treated controls and untreated DSS mice [means \pm SD (\%): DSS (anti-IL-6), $8.813 \pm 3.65$; DSS (isotype), $15.70 \pm 1.79 ; P=0.003$; DSS (naïve), $13.78 \pm 2.39 ; P=0.049$ ] (Figure 7A). However, there was no difference in the proportions of monocytes in the lungs of anti-IL-6-treated DSS mice, compared with isotype-treated controls (Figure 7B). Given the increase in neutrophil recruiting mediators $\mathrm{KC}$ and CCL2 observed in the lungs of DSS colitis animals, it was next examined whether IL-6 treatment had any effect on CCL2 (Figure 7C) and KC (Figure 7D) protein levels. No significant differences were observed with anti-IL-6 treatment compared with isotype controls. IL-1 $\beta$ was also examined in the lungs of anti-IL-6-treated DSS animals, but no differences were found compared with untreated or isotype control groups (Figure 7E). It was next investigated whether the decrease in neutrophils entering the lung was a consequence of an overall decrease in circulating leukocytes because of neutralization of IL-6. The proportion and numbers of circulating neutrophils were significantly decreased after anti-IL-6 antibody administration, compared with isotype-treated groups [means \pm SD (\%): DSS (isotype), $23.83 \pm 9.77$; DSS (anti-IL-6), $12.00 \pm 3.23 ; P=0.0297$ ] (Figure 7F). In 

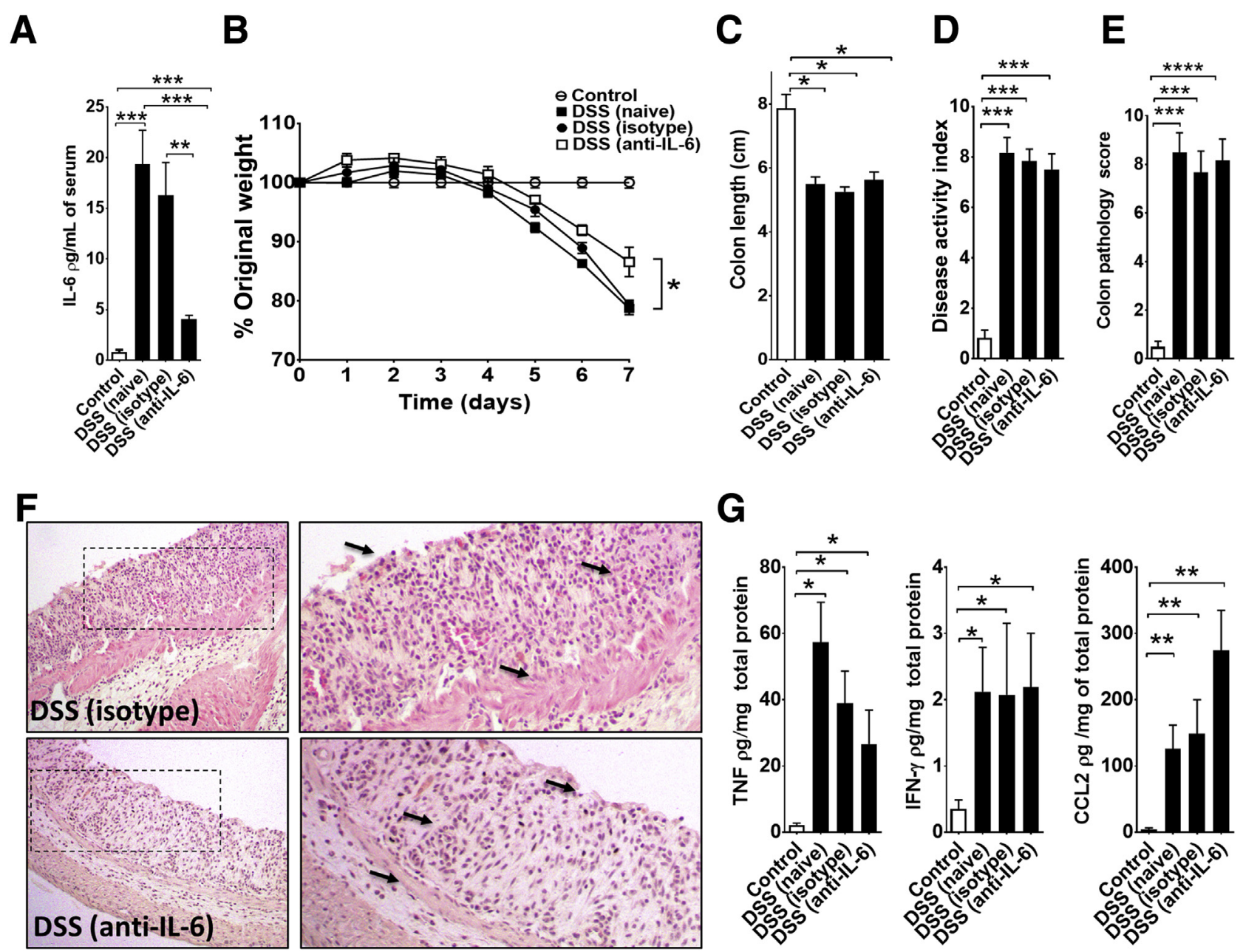

G
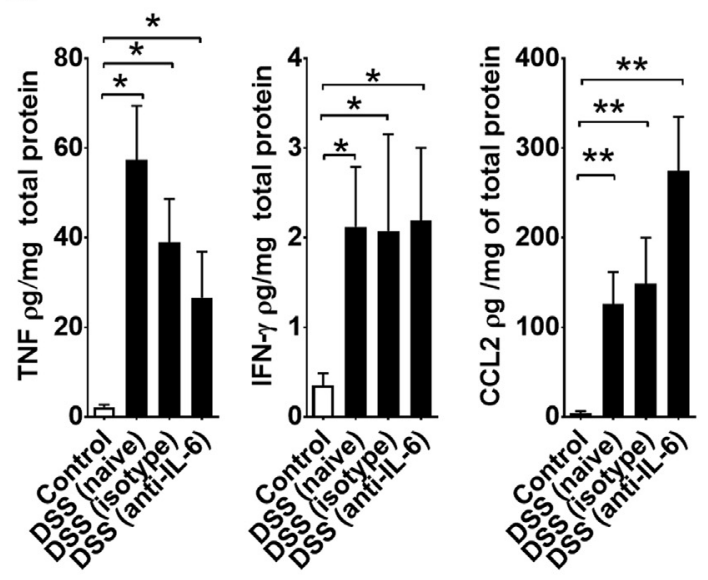

Figure 6 Influence of IL- 6 depletion on lung and colon pathology in DSS colitis. DSS-treated animals and DSS groups were treated with anti-IL-6 antibody or isotype control antibody. A: Serum IL-6 levels were measured by cytometric bead array. B-D: Animals were monitored for weight loss normalized to naïve controls (B), colon length (C), and disease activity index (D), assessed by stool consistency, occult blood, colon shortening, and weight loss. E: Quantitative analysis of colon histopathology. F: Representative images of histopathology observed in the colon; arrows denote epithelial damage and immune infiltration. Boxed areas in the left column are shown at higher magnification in the right column $(650 \times 275-\mu \mathrm{m}$ area). G: Tumor necrosis factor (TNF)- $\alpha$, interferon (IFN) $-\gamma$, and chemokine (C-C motif) ligand (CCL) 2 protein levels in the colon, measured by cytometric bead array and expressed as cytokine/total protein. Statistical analysis was performed with one-way analysis of variance $(\mathbf{A}, \mathbf{C}-\mathbf{E}$, and $\mathbf{G})$ or two-way analysis of variance (B). Data are expressed as means \pm SEM from two separate experiments (A-E and $\mathbf{G}) . n=8$ (A-E and $\mathbf{G}$ ). ${ }^{*} P<0.05,{ }^{* *} P<0.01,{ }^{* * *} P<0.005$, and ${ }^{* * * *} P<0.001$ versus control. Original magnification: $\times 20(\mathbf{F}$, left column $) ; \times 10(\mathbf{F}$, right column).

contrast, there was no significant difference in the proportion or numbers of circulating monocytes in anti-IL-6-treated animals compared with isotype controls (Figure $7 \mathrm{G}$ ).

\section{IL-6 Mediates Egress of Neutrophils from the Bone Marrow during Colitis}

Because colitis induced the proliferation of neutrophil progenitor cells in the bone marrow, we hypothesized that the increase in neutrophils in the circulatory system was a result of IL-6-mediated stimulation of myeloid progenitor cells. To test this hypothesis, it was examined whether IL-6 neutralization influenced neutrophil development in the bone marrow of DSS animals. Interestingly, anti-IL6-treated animals had significantly higher bone marrow multipotent progenitor cell proportions compared with isotype-treated groups [means \pm SD: DSS (isotype), $4.72 \pm 1.89$; DSS (anti-IL-6), $11.34 \pm 1.31 ; P<0.0001]$ (Figure $7 \mathrm{H}$ ). Furthermore, the proportion of mature neutrophils in the bone of anti-IL-6-treated animals was significantly greater than in isotype-treated groups [means \pm SD: DSS (isotype), $14.63 \pm 7.72$; DSS (anti-IL-6), $39.30 \pm 6.28 ; P=0.026$ ] (Figure 7I). Together, these data suggest that IL-6 signaling during DSS colitis mediates egress of neutrophils from the bone marrow, which contributes to systemic and extraintestinal pathology during intestinal inflammation.

\section{Discussion}

The aim of this study was to identify and characterize lung immunopathology associated with animal models of colitis. 
A

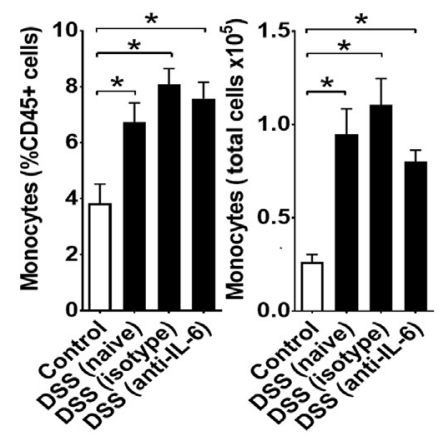

$\mathbf{F}$
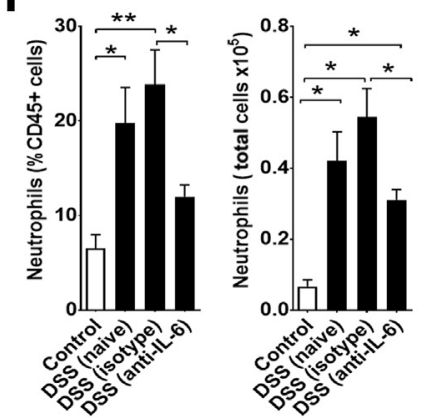

B

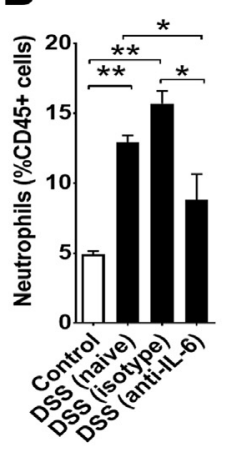

G

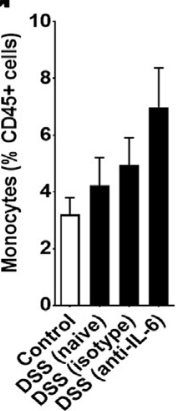

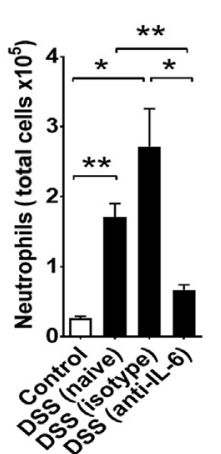

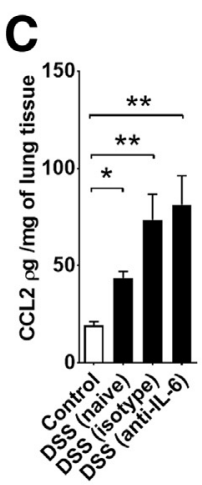

D
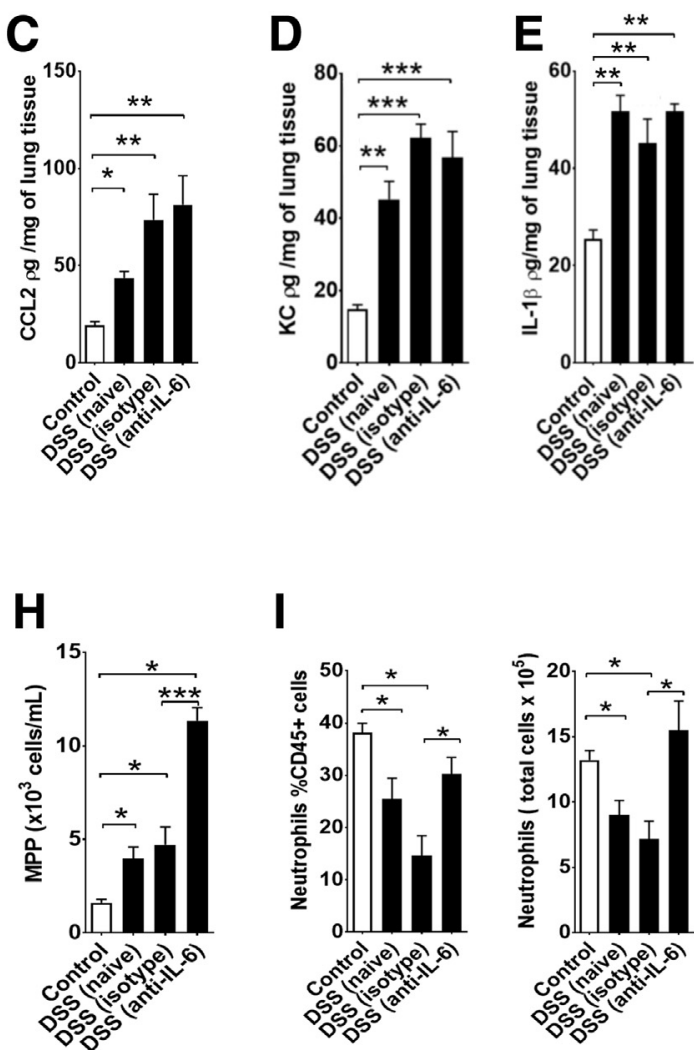

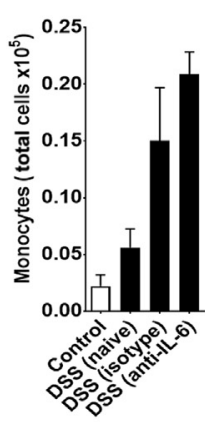

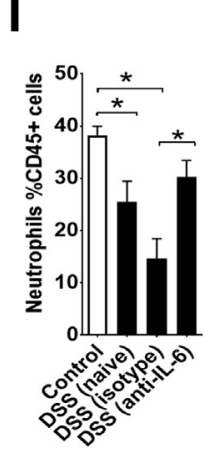

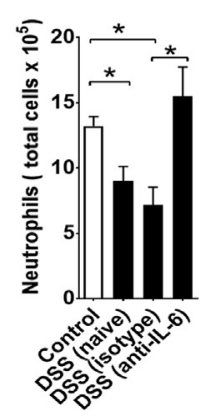

Figure 7 Influence of IL- 6 depletion on lung, blood, and bone marrow cellularity in DSS colitis. DSS animals were treated with anti-IL-6 or isotype control and compared with healthy control and naïve DSS animals. CD45 ${ }^{\text {ve }}$ cells were isolated from the lungs, blood, and bone marrow and assessed by flow cytometry. A and B: The proportion and total cell number of neutrophils (A) and monocytes (B) in the lungs. C-E: Protein levels of chemokine (C-C motif) ligand (CCL) 2 (C), keratinocyte chemoattractant (D), and IL-1 $\beta(\mathbf{E})$ in the lungs, as measured by cytometric bead array. $\mathbf{F}$ and $\mathbf{G}$ : The proportion and total cell number of neutrophils (F) and monocytes $(\mathbf{G})$ in the blood. H: The number of multipotent progenitor (MPP; Lin $^{-} \mathrm{CD}_{48}{ }^{+} \mathrm{CD} 150^{-}$) cells in the bone marrow. I: The proportion and total cell number of mature neutrophil levels in the bone marrow. All data represented as means \pm SEM from two separate experiments (A-I). $n=8(\mathbf{A}-\mathbf{I}) .{ }^{*} P<0.05,{ }^{*} P<<0.01$, and ${ }^{* *} * P<0.005$ (one-way analysis of variance).

The loss of intestinal permeability in murine models of colitis is associated with increased bacteremia, characterized by recovery of bacterial CFUs from distal organs. ${ }^{31}$ Herein, guided by the prevalence of neutrophilic pulmonary pathology reported in IBD patients, we hypothesized that the bacteremia and systemic inflammation in animal models of colitis would predispose to lung pathologies identifiable by structural and biochemical assessment. A vascular accumulation of neutrophils common to the DSS and TNBS models of colitis was identified. Neutrophil recruitment to the lung was associated with increased bacteria in the lung and elevated levels of IL-1 $\beta$, CCL2, and KC, and it was dependent on systemic IL-6 signaling. However, ablation of systemic IL-6 did not prevent increases in inflammatory mediators in the lung, suggesting that pulmonary manifestations of IBD are a consequence of overall systemic inflammation.

Pulmonary pathologies have previously been identified in rat models of colitis, with elevated intercellular adhesion molecule 1 identified in lung tissue sections of a rat TNBS model $^{43}$ and increases in TNF- $\alpha$ and vascular endothelial growth factor in both rat DSS and TNBS models. ${ }^{44}$ More important, both of these models suggested vascular involvement in the disease, but they did not identify a mechanism analogous to the pulmonary manifestations observed in IBD patients. In the current study, the predominance of neutrophils in the lung infiltrate of the colitis models is analogous to pulmonary pathologies associated with IBD. For instance, bronchiectasis and chronic bronchitis are two of the most common pulmonary manifestations of IBD, irrespective of smoking status. ${ }^{27}$ Both are associated with elevated CCL2 and IL-8 and neutrophil extravasation into the respiratory system, ${ }^{45}$ with the subsequent activation of these cells inducing structural pathologies. The inflammation observed in the murine DSS and TNBS models was associated with increases in CCL2 and KC, along with infiltration of neutrophils in the lung. Both CCL2 and $\mathrm{KC}$ are key mediators of neutrophil recruitment during pulmonary infection. ${ }^{42,46}$ Herein, we hypothesize that increases in intestinal permeability and bacteremia drive pyrexia, which, coupled with secondary local inflammation in the lung, activates circulating primed neutrophils. In support of this hypothesis, targeted depletion of the key pyrogen IL-6 was sufficient to inhibit egress of neutrophils from the bone marrow in DSS animals, but did not reduce local inflammatory 
signaling in the lung. In addition, although anti-IL-6 treatment did not affect GI inflammation, it reduced colitis-associated wasting, an observation consistent with previous studies. ${ }^{47-49}$ The ability of IL-6 blockade to reduce wasting in colitis may be attributed to the pyrogenic effect elicited by IL- $6 .{ }^{50}$ Indeed, IL-6 is associated with bacteremia and pyrexia in mouse models of colitis. $^{31}$ More important, lipopolysaccharide-induced toll-like receptor 4 signaling drives the synthesis of pyrogenic cytokines, including IL-6, which is a key mediator of the pyrexic response. ${ }^{51}$ Previous studies have demonstrated that treatment with anti-IL-6 neutralizing antibodies prevents the development of lipopolysaccharide-induced fever in rodents, ${ }^{52}$ and this is mirrored in IL-6-deficient animals. ${ }^{53}$ In both cases, and despite the lack of a fever response, TNF- $\alpha$ and IL- $1 \beta$ levels increased with lipopolysaccharide challenge, suggesting a central importance for IL-6 in mediating fever. Indeed, evidence from experiments in peripheral blood mononuclear cell cultures suggests that IL- 6 can suppress both IL- $1 \beta$ and TNF- $\alpha$ at the transcriptional level,,${ }^{54}$ and Diao and Kohanawa ${ }^{55}$ have shown that in septic shock models, IL-6 limits infection through suppression of TNF- $\alpha$. This may explain the absence of a TNF- $\alpha$ response in this model, because IL- 6 may be suppressing TNF- $\alpha$ responses.

Systemic IL-6 inhibition has previously been shown to be protective in DSS colitis, with reduced severity of colitis reported in IL-6-deficient mice ${ }^{47,56}$ and attenuated disease associated with antibody depletion of both IL- $6^{48}$ and the IL-6 signal transducer, gp130. ${ }^{49}$ Although, herein, anti-IL-6 treatment had no influence on the severity of GI pathology, this may be attributed to the timing of the interventions, because anti-IL-6 antibody was administered after colitis was initiated. In studies by Sander et $\mathrm{al}^{49}{ }^{49}$ where gp130, the common signal transducer for IL-6, was deleted in a DSS model, loss of IL-6 signaling delayed and attenuated acute disease, but only marginally affected leukocyte infiltration by day 7. Despite this, loss of IL-6 reduced circulating leukocytes and DSS-induced wasting. The study concluded that IL-6 was important for intestinal leukocyte recruitment in the acute phase of disease, ${ }^{49}$ and this is largely attributed to early activation of colonic resident myeloid. ${ }^{49}$ Colitis also alters hematopoietic processes in the bone marrow, which enhances production of granulocytes and monocytes that are released in the circulatory system. ${ }^{57}$ However, the mechanism for this process is not well understood and the specific soluble mediators that promote the release of neutrophils into the circulation during colitis are not known. Systemic levels of IL-6, driving fever, can increase circulating neutrophils, ${ }^{58}$ which, in turn, may lead to accumulation of neutrophils within peripheral tissues, including the lung. ${ }^{26,59}$ Neutralization of IL-6 attenuated the systemic neutrophilia associated with colitis and was associated with an increase in mature neutrophils in the bone marrow. The role of IL-6 in controlling granulopoiesis and, by extension, accumulation of neutrophils at inflammatory sites has been shown by Liu et $\mathrm{al}^{60}$ and Chou et al. ${ }^{61}$ Under homeostatic conditions, neutrophil egress from the bone marrow is mediated by $\mathrm{C}-\mathrm{X}-\mathrm{C}$ chemokine receptor $4 /$ stromal cell-derived factor 1 (SDF-1) interactions, but in the context of inflammation, several chemokines may enable chemotaxis of neutrophils across the bone marrow sinusoidal endothelium. These data may indicate that, although IL-6 is important for driving neutrophil egress during bacteremia/ pyrexia, it is not key to the increase in granulocytes in the bone marrow. Alternatively, the timing of the treatment, after induction of colitis, may have facilitated an early IL6-mediated accumulation of neutrophils in the bone marrow, but prevented the post-treatment release into the circulation.

Overall, these data suggest that pyrexia and systemic bacteremia attributable to loss of intestinal barrier integrity play a role in extraintestinal manifestation of colitis. We propose a two-hit hypothesis, facilitated by both increases in the pyrogen IL- 6 and local secretion of neutrophil chemokines, such as IL-1 $\beta, \mathrm{KC} / \mathrm{IL}-8$, and CCL2. The importance of a local factor is supported by the observation that in adoptive transfer of neutrophils from DSS animals, there was significantly increased homing to the lung in DSS recipient animals but not healthy controls. Because the population of neutrophils transferred from healthy to DSS animals did not accumulate in the lung in significant numbers, it would appear that neither systemic responses nor local responses in isolation are sufficient to promote pulmonary manifestations of colitis. Although IL-6 does not directly mediate tissue pathology, depletion of systemic IL-6 reduces the number of neutrophils in the circulation that can migrate to the lung. In considering the clinical relevance of these findings, it is worth noting that bacteremia and fever are common pathologies in episodes of IBD relapse, and IBD patients with pulmonary pathology commonly present with bronchiectasis and chronic bronchitis, both of which are neutrophil-driven diseases. Whether these pathways are specific to pulmonary manifestations of IBD is unclear, but there is evidence of neutrophil involvement in the pathology of hepatic morbidity in IBD. ${ }^{62}$ We have recently shown that lung disease, caused by chronic cigarette smoke, leads to systemic ischemia that drives intestinal dysfunction, predisposing to colitis. ${ }^{63}$ Whether pulmonary damage initiated by colitis may perpetuate disease in a similar manner is unclear, but would be worth investigating. The utility of targeting IL-6 as an intervention for pyrexic disease has already been established, and the IL- 6 receptor antagonist tocilizumab has been investigated as a therapy for pyrexia and cachexia associated with cancers. ${ }^{64,65}$ In the context of IBD, our studies indicate that targeting IL- 6 for the early management of bacteremia in IBD could reduce the risk of developing extraintestinal complications.

\section{Supplemental Data}

Supplemental material for this article can be found at https://doi.org/10.1016/j.ajpath.2018.03.016. 


\section{References}

1. Levine JS, Burakoff R: Extraintestinal manifestations of inflammatory bowel disease. Gastroenterol Hepatol (N Y) 2011, 7:235-241

2. Danese S, Semeraro S, Papa A, Roberto I, Scaldaferri F, Fedeli G, Gasbarrini G, Gasbarrini A: Extraintestinal manifestations in in flammatory bowel disease. World J Gastroenterol 2005, 11: $7227-7236$

3. Black H, Mendoza M, Murin S: Thoracic manifestations of inflammatory bowel disease. Chest 2007, 131:524-532

4. Eade OE, Smith CL, Alexander JR, Whorwell PJ: Pulmonary function in patients with inflammatory bowel disease. Am J Gastroenterol 1980, 73:154-156

5. Herrlinger KR, Noftz MK, Dalhoff K, Ludwig D, Stange EF, Fellermann K: Alterations in pulmonary function in inflammatory bowel disease are frequent and persist during remission. Am J Gastroenterol 2002, 97:377-381

6. Marvisi M, Borrello PD, Brianti M, Fornarsari G, Marani G, Guariglia A: Changes in the carbon monoxide diffusing capacity of the lung in ulcerative colitis. Eur Respir J 2000, 16:965-968

7. Ates F, Karincaoglu M, Hacievliyagil SS, Yalniz M, Seckin Y: Alterations in the pulmonary function tests of inflammatory bowel diseases. Turk J Gastroenterol 2011, 22:293-299

8. Bonniere $\mathrm{P}$, Wallaert B, Cortot A, Marchandise X, Riou Y, Tonnel AB, Colombel JF, Voisin C, Paris JC: Latent pulmonary involvement in Crohn's disease: biological, functional, bronchoalveolar lavage and scintigraphic studies. Gut 1986, 27:919-925

9. Tzanakis N, Bouros D, Samiou M, Panagou P, Mouzas J, Manousos O, Siafakas N: Lung function in patients with inflammatory bowel disease. Respir Med 1998, 92:516-522

10. Keely S, Talley NJ, Hansbro PM: Pulmonary-intestinal cross-talk in mucosal inflammatory disease. Mucosal Immunol 2012, 5:7-18

11. Zhao Y, Wang J, Liu Z, Lin H, Shi Y, Sun X: Pulmonary dysfunction in 114 patients with inflammatory bowel disease. Medicine (Baltimore) 2017, 96:e6808

12. Wang H, Liu JS, Peng SH, Deng XY, Zhu DM, Javidiparsijani S, Wang GR, Li DQ, Li LX, Wang YC, Luo JM: Gut-lung crosstalk in pulmonary involvement with inflammatory bowel diseases. World J Gastroenterol 2013, 19:6794-6804

13. Romano C, Cardile S: Pulmonary implications in inflammatory bowel disease: not a rare event. Expert Opin Drug Saf 2016, 15:1001-1002

14. Majewski S, Piotrowski W: Pulmonary manifestations of inflammatory bowel disease. Arch Med Sci 2015, 11:1179-1188

15. Ji XQ, Wang LX, Lu DG: Pulmonary manifestations of inflammatory bowel disease. World J Gastroenterol 2014, 20:13501-13511

16. Ji XQ, Ji YB, Wang SX, Zhang CQ, Lu DG: Alterations of pulmonary function in patients with inflammatory bowel diseases. Ann Thorac Med 2016, 11:249-253

17. Gut G, Ben-Tov A, Lahad A, Soferman R, Cohen S, Tauman R, Sivan Y: Pulmonary functions in children with inflammatory bowel disease. Eur J Gastroenterol Hepatol 2016, 28:708-713

18. Gelberg J, Stather DR: Pulmonary manifestations of inflammatory bowel disease. Can Respir J 2013, 20:84

19. Al-Mendalawi MD: Alterations of pulmonary function in patients with inflammatory bowel diseases. Ann Thorac Med 2017, 12:129

20. Lodes MJ, Cong Y, Elson CO, Mohamath R, Landers CJ, Targan SR, Fort M, Hershberg RM: Bacterial flagellin is a dominant antigen in Crohn disease. J Clin Invest 2004, 113:1296-1306

21. Pastor Rojo O, Lopez San Roman A, Albeniz Arbizu E, de la Hera Martinez A, Ripoll Sevillano E, Albillos Martinez A: Serum lipopolysaccharide-binding protein in endotoxemic patients with inflammatory bowel disease. Inflamm Bowel Dis 2007, 13: 269-277

22. Gardiner KR, Halliday MI, Barclay GR, Milne L, Brown D, Stephens S, Maxwell RJ, Rowlands BJ: Significance of systemic endotoxaemia in inflammatory bowel disease. Gut 1995, 36:897-901
23. Sheth T, Pitchumoni CS, Das KM: Musculoskeletal manifestations in inflammatory bowel disease: a revisit in search of immunopathophysiological mechanisms. J Clin Gastroenterol 2014, 48:308-317

24. Tornai T, Palyu E, Vitalis Z, Tornai I, Tornai D, Antal-Szalmas P, Norman GL, Shums Z, Veres G, Dezsofi A, Par G, Par A, Orosz P, Szalay F, Lakatos PL, Papp M: Gut barrier failure biomarkers are associated with poor disease outcome in patients with primary sclerosing cholangitis. World J Gastroenterol 2017, 23:5412-5421

25. Pietrzak D, Pietrzak A, Krasowska D, Borzecki A, FranciszkiewiczPietrzak K, Polkowska-Pruszynska B, Baranowska M, Reich K: Digestive system in psoriasis: an update. Arch Dermatol Res 2017, 309:679-693

26. Rice P, Martin E, He JR, Frank M, DeTolla L, Hester L, O'Neill T, Manka C, Benjamin I, Nagarsekar A, Singh I, Hasday JD: Febrilerange hyperthermia augments neutrophil accumulation and enhances lung injury in experimental gram-negative bacterial pneumonia. J Immunol 2005, 174:3676-3685

27. Mateer SW, Maltby S, Marks E, Foster PS, Horvat JC, Hansbro PM, Keely S: Potential mechanisms regulating pulmonary pathology in inflammatory bowel disease. J Leukoc Biol 2015, 98:727-737

28. Richman-Eisenstat JB, Jorens PG, Hebert CA, Ueki I, Nadel JA: Interleukin-8: an important chemoattractant in sputum of patients with chronic inflammatory airway diseases. Am J Physiol 1993, 264:L413-L418

29. Eller J, Lapa e Silva JR, Poulter LW, Lode H, Cole PJ: Cells and cytokines in chronic bronchial infection. Ann N Y Acad Sci 1994, 725:331-345

30. Alex P, Zachos NC, Nguyen T, Gonzales L, Chen TE, Conklin LS, Centola M, Li X: Distinct cytokine patterns identified from multiplex profiles of murine DSS and TNBS-induced colitis. Inflamm Bowel Dis 2009, 15:341-352

31. Keely S, Campbell EL, Baird AW, Hansbro PM, Shalwitz RA, Kotsakis A, McNamee EN, Eltzschig HK, Kominsky DJ, Colgan SP: Contribution of epithelial innate immunity to systemic protection afforded by prolyl hydroxylase inhibition in murine colitis. Mucosal Immunol 2014, 7:114-123

32. Marks E, Naudin C, Nolan G, Goggins BJ, Burns G, Mateer SW, Latimore JK, Minahan K, Plank M, Foster PS, Callister R, Veysey M, Walker MM, Talley NJ, Radford-Smith G, Keely S: Regulation of IL-12p40 by HIF controls Th1/Th17 responses to prevent mucosal inflammation. Mucosal Immunol 2017, 10: $1224-1236$

33. Marks E, Goggins BJ, Cardona J, Cole S, Minahan K, Mateer S, Walker MM, Shalwitz R, Keely S: Oral delivery of prolyl hydroxylase inhibitor: AKB-4924 promotes localized mucosal healing in a mouse model of colitis. Inflamm Bowel Dis 2015, 21:267-275

34. Campbell EL, MacManus CF, Kominsky DJ, Keely S, Glover LE, Bowers BE, Scully M, Bruyninckx WJ, Colgan SP: Resolvin E1induced intestinal alkaline phosphatase promotes resolution of inflammation through LPS detoxification. Proc Natl Acad Sci U S A 2010, 107:14298-14303

35. Horvat JC, Beagley KW, Wade MA, Preston JA, Hansbro NG, Hickey DK, Kaiko GE, Gibson PG, Foster PS, Hansbro PM: Neonatal chlamydial infection induces mixed T-cell responses that drive allergic airway disease. Am J Respir Crit Care Med 2007, 176:556-564

36. Liu G, Cooley MA, Nair PM, Donovan C, Hsu AC, Jarnicki AG, Haw TJ, Hansbro NG, Ge Q, Brown AC, Tay H, Foster PS, Wark PA Horvat JC, Bourke JE, Grainge CL, Argraves WS, Oliver BG, Knight DA, Burgess JK, Hansbro PM: Airway remodelling and inflammation in asthma are dependent on the extracellular matrix protein fibulin-1c. J Pathol 2017, 243:510-523

37. Beckett EL, Stevens RL, Jarnicki AG, Kim RY, Hanish I, Hansbro NG, Deane A, Keely S, Horvat JC, Yang M, Oliver BG, van Rooijen N, Inman MD, Adachi R, Soberman RJ, Hamadi S, Wark PA, Foster PS, Hansbro PM: A new short-term mouse model of chronic obstructive pulmonary disease identifies a role for mast cell tryptase in pathogenesis. J Allergy Clin Immunol 2013, 131:752-762

38. Liu G, Cooley MA, Jarnicki AG, Hsu AC, Nair PM, Haw TJ, Fricker M, Gellatly SL, Kim RY, Inman MD, Tjin G, Wark PA, 
Walker MM, Horvat JC, Oliver BG, Argraves WS, Knight DA, Burgess JK, Hansbro PM: Fibulin-1 regulates the pathogenesis of tissue remodeling in respiratory diseases. JCI Insight 2016, 1:e86380

39. Maltby S, Hansbro NG, Tay HL, Stewart J, Plank M, Donges B, Rosenberg HF, Foster PS: Production and differentiation of myeloid cells driven by proinflammatory cytokines in response to acute pneumovirus infection in mice. J Immunol 2014, 193: 4072-4082

40. Miyabe Y, Kim ND, Miyabe C, Luster AD: Studying neutrophil migration in vivo using adoptive cell transfer. Methods Mol Biol 2016, 1407:179-194

41. Neurath MF: Cytokines in inflammatory bowel disease. Nat Rev Immunol 2014, 14:329-342

42. van Zoelen MA, Verstege MI, Draing C, de Beer R, van't Veer C, Florquin S, Bresser P, van der Zee JS, te Velde AA, von Aulock S, van der Poll T: Endogenous MCP-1 promotes lung inflammation induced by LPS and LTA. Mol Immunol 2011, 48: $1468-1476$

43. Liu Y, Wang XY, Yang X, Jing S, Zhu L, Gao SH: Lung and intestine: a specific link in an ulcerative colitis rat model. Gastroenterol Res Pract 2013, 2013:124530

44. Aydin B, Songur Y, Songur N, Aksu O, Senol A, Ciris IM, Sutcu R: Investigation of pulmonary involvement in inflammatory bowel disease in an experimental model of colitis. Korean J Intern Med 2016, 31:853-859

45. Rose CE Jr, Sung SS, Fu SM: Significant involvement of CCL2 (MCP-1) in inflammatory disorders of the lung. Microcirculation 2003, 10:273-288

46. Singh IS, Gupta A, Nagarsekar A, Cooper Z, Manka C, Hester L, Benjamin IJ, He JR, Hasday JD: Heat shock co-activates interleukin-8 transcription. Am J Respir Cell Mol Biol 2008, 39: 235-242

47. Naito Y, Takagi T, Uchiyama K, Kuroda M, Kokura S, Ichikawa H, Yanagisawa R, Inoue K, Takano H, Satoh M, Yoshida N, Okanoue T, Yoshikawa T: Reduced intestinal inflammation induced by dextran sodium sulfate in interleukin-6-deficient mice. Int J Mol Med 2004, 14:191-196

48. Sommer J, Engelowski E, Baran P, Garbers C, Floss DM, Scheller J: Interleukin-6, but not the interleukin-6 receptor plays a role in recovery from dextran sodium sulfate-induced colitis. Int J Mol Med 2014, 34:651-660

49. Sander LE, Obermeier F, Dierssen U, Kroy DC, Singh AK, Seidler U, Streetz KL, Lutz HH, Muller W, Tacke F, Trautwein C: Gp130 signaling promotes development of acute experimental colitis by facilitating early neutrophil/macrophage recruitment and activation. $\mathrm{J}$ Immunol 2008, 181:3586-3594

50. Netea MG, Kullberg BJ, Van der Meer JWM: Circulating cytokines as mediators of fever. Clin Infect Dis 2000, 31:S178-S184

51. Evans SS, Repasky EA, Fisher DT: Fever and the thermal regulation of immunity: the immune system feels the heat. Nat Rev Immunol 2015, 15:335-349

52. Cartmell T, Poole S, Turnbull AV, Rothwell NJ, Luheshi GN: Circulating interleukin-6 mediates the febrile response to localised inflammation in rats. J Physiol 2000, 526:653-661
53. Kozak W, Kluger MJ, Soszynski D, Conn CA, Rudolph K, Leon LR, Zheng H: IL- 6 and IL-1 beta in fever: studies using cytokine-deficient (knockout) mice. Ann N Y Acad Sci 1998, 856:33-47

54. Schindler R, Mancilla J, Endres S, Ghorbani R, Clark SC, Dinarello CA: Correlations and interactions in the production of interleukin-6 (IL-6), $\mathrm{IL}-1$, and tumor necrosis factor (TNF) in human blood mononuclear cells: IL-6 suppresses IL-1 and TNF. Blood 1990, 75:40-47

55. Diao H, Kohanawa M: Endogenous interleukin-6 plays a crucial protective role in streptococcal toxic shock syndrome via suppression of tumor necrosis factor alpha production. Infect Immun 2005, 73 : $3745-3748$

56. Grivennikov S, Karin E, Terzic J, Mucida D, Yu G-Y, Vallabhapurapu S, Scheller J, Rose-John S, Cheroutre H, Eckmann L, Karin M: IL-6 and Stat3 are required for survival of intestinal epithelial cells and development of colitis-associated cancer. Cancer Cell 2009, 15:103-113

57. Trottier MD, Irwin R, Li Y, McCabe LR, Fraker PJ: Enhanced production of early lineages of monocytic and granulocytic cells in mice with colitis. Proc Natl Acad Sci U S A 2012, 109:16594-16599

58. Capitano ML, Nemeth MJ, Mace TA, Salisbury-Ruf C, Segal BH, McCarthy PL, Repasky EA: Elevating body temperature enhances hematopoiesis and neutrophil recovery after total body irradiation in an IL-1-, IL-17-, and G-CSF-dependent manner. Blood 2012, 120: $2600-2609$

59. Tulapurkar ME, Almutairy EA, Shah NG, He JR, Puche AC, Shapiro P, Singh IS, Hasday JD: Febrile-range hyperthermia modifies endothelial and neutrophilic functions to promote extravasation. Am J Respir Cell Mol Biol 2012, 46:807-814

60. Liu F, Poursine-Laurent J, Wu HY, Link DC: Interleukin-6 and the granulocyte colony-stimulating factor receptor are major independent regulators of granulopoiesis in vivo but are not required for lineage commitment or terminal differentiation. Blood 1997, 90: $2583-2590$

61. Chou DB, Sworder B, Bouladoux N, Roy CN, Uchida AM, Grigg M, Robey PG, Belkaid Y: Stromal-derived IL-6 alters the balance of myeloerythroid progenitors during Toxoplasma gondii infection. J Leukoc Biol 2012, 92:123-131

62. Seibold F, Weber P, Schoning A, Mork H, Goppel S, Scheurlen M: Neutrophil antibodies (pANCA) in chronic liver disease and inflammatory bowel disease: do they react with different antigens? Eur J Gastroenterol Hepatol 1996, 8:1095-1100

63. Fricker M, Goggins BJ, Mateer S, Jones B, Kim RY, Gellatly SL, Jarnicki AG, Powell N, Oliver BG, Radford-Smith G, Talley NJ, Walker MM, Keely S, Hansbro PM: Chronic cigarette smoke exposure induces systemic hypoxia that drives intestinal dysfunction. JCI Insight 2018, [Epub ahead of print] doi:10.1172/jci.insight.94040

64. Grupp SA, Kalos M, Barrett D, Aplenc R, Porter DL, Rheingold SR, Teachey DT, Chew A, Hauck B, Wright JF, Milone MC, Levine BL, June CH: Chimeric antigen receptor-modified $\mathrm{T}$ cells for acute lymphoid leukemia. N Engl J Med 2013, 368:1509-1518

65. Ando K, Takahashi F, Kato M, Kaneko N, Doi T, Ohe Y, Koizumi F, Nishio K, Takahashi K: Tocilizumab, a proposed therapy for the cachexia of Interleukin6-expressing lung cancer. PLoS One 2014, 9: e102436 